\title{
A Literature Review of Cardiovascular Disease Management Programs in Managed Care Populations
}

\author{
SHETA ARA, PharmD
}

\begin{abstract}
OBJECTIVES: (1) To review the literature on cardiovascular disease management programs in managed care populations, (2) compare the rigor of the studies and their findings by disease state, and (3) posit directions for future research.

SUMMARY: A total of 20 studies conducted in managed care populations were reviewed: 5 in patients with congestive heart failure (CHF), 9 in hypertensive patients, and 6 in hyperlipidemia and/or coronary artery disease (hyperlipidemiaCAD) patients. Management of CHF involved multifaceted programs that included the participation of multiple health care professionals, patient and physician education, promotion of intensive drug therapy and lifestyle modifications, and close patient monitoring. The most common CHF management strategies were case management and physician education, with an emphasis on close patient monitoring. Hypertension and hyperlipidemia-CAD intervention programs focused on chronic outpatient management and regular follow-up, with an emphasis on selfmanagement skills. These programs were managed through regular and periodic interventions, including pharmacist-managed clinics and automated provider notices. Many of the studies employed "before-after" comparisons in the absence of a truly experimental design and posed significant limitations due to variations in the outcomes measured, lack of transparent disease severity stratification, and variation across types of managed care organizations.

CONCLUSION: A number of cardiovascular disease management strategies in the literature reported promising results. Many of the multidisciplinary CHF disease management programs were more complex than were programs for hypertension and hyperlipidemia-CAD, due, at least in part, to the nature and severity of the disease. A lack of agreement on appropriate economic and clinical outcomes for evaluating the effectiveness of cardiovascular disease management strategies is readily apparent.
\end{abstract}

KEYWORDS: Cardiovascular disease, Coronary artery disease, Hypertension, Congestive heart failure, Hyperlipidemia, Disease management, Intervention programs, Managed care

J Manag Care Pharm. 2004;10(4):326-44

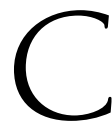
ardiovascular disease (CVD) includes heart disease (i.e., myocardial infarction and angina), stroke, hypertension, congestive heart failure (CHF), hardening of the arteries, and other circulatory system diseases. CVD is the number one cause of death in America, responsible for more than $40 \%$ of annual deaths. An average of 1 death due to CVD occurs every 33 seconds in the United States. ${ }^{1}$

In addition to mortality, poorly managed CVD can lead to significant long-term disability from the complications of heart attacks, strokes, heart failure, and end-stage renal disease. ${ }^{2}$ Costs due to death and disability are enormous; the estimated medical and disability cost (year 2002) of CVD-related disorders amounts to $\$ 330$ billion. The American Heart Association (AHA) spent approximately \$382 million during 2000 and 2001 on CVD research support, professional and public education, and community service programs. ${ }^{1}$ CVD is a serious public health issue that requires greater attention to promote awareness and treatment, both to health care providers and the public.

Progress in managing the CVD population may be advanced by closely examining the results of previous studies in this arena. The purpose of this article is to describe the results of a literature review on disease management (DM) strategies targeting CVD (i.e., hypertension, congestive heart failure, and hyperlipidemia and/or coronary artery disease [CAD]) in managed care populations, compare the rigor of the studies and their findings by disease state, and posit directions for future research.

\section{Disease Management}

DM is characterized by a systematic population-based approach to identify persons at risk, implement detailed programs of care, measure outcomes of interest (i.e., clinical, economic, or humanistic), and achieve continuous quality improvement (QI) in the care processes that contribute to these outcomes. ${ }^{3} \mathrm{DM}$, the preferred acronym of the Disease Management Association of America, is further defined as a support system for health care providers and patient relationships with an emphasis on the prevention of exacerbations and complications of diseases using evidence-based guidelines and patient empowerment strategies. ${ }^{4}$ Traditionally, the management of diseases involved individual assessment and treatment of patients at the primary care point of service. This approach results in variations in patient assessment and management that leads in some cases to inefficient delivery of care and suboptimal outcomes. Current DM models can overcome some variation in care processes and suboptimal outcomes. 
Present DM practice is typically a systematic model where clinical services are supported by information that is computerized, summarized, and shared. Computerized clinical guidelines and treatment algorithms streamline care and assessment of health outcomes. These programs are designed to meet the specific needs of particular institutions, thus allowing them to tailor their intervention strategies. Examples of interventions include appropriate use of clinical guidelines, patient education in self-management skills, reminder systems for health care delivery, or case management; many of the interventions are designed for delivery at the point of care. ${ }^{3}$ A recent survey indicates that the goals considered "very important" for implementing interventions are to improve the quality of care, increase patient satisfaction, control the cost of care, and meet the national standards of care. ${ }^{5}$

\section{The Role of Managed Care in Disease Management}

The primary goal of managed care organizations (MCOs) is to provide high-quality, cost-effective health care services. ${ }^{6,7}$ Subsequently, DM and QI programs have become increasingly common in managed care settings. ${ }^{5,31} \mathrm{DM}$ can benefit an MCO by managing rising costs of chronic diseases while obtaining accreditation by attaining national standards of care, especially those set forth by the National Commission for Quality Assurance..$^{5}$ To obtain accreditation, health care systems must demonstrate improvement in the quality of care achieved by self-evaluation to determine deficiencies, the development and implementation of initiatives to improve outcomes, and the reevaluation of initiatives to measure their impact. ${ }^{8}$ All of these may be accomplished through DM strategies. The chronic nature of CVD and its contribution to high medical resource utilization, costs, and high rates of morbidity and mortality make it an ideal disease category upon which MCOs may focus.

MCOs are in an ideal position to manage CVD because they have the potential for innovative population management strategies based on the following characteristics:

- MCOs have access to a large, well-defined population of enrollees.

- MCOs have electronic databases that can link information for members, health care providers, care processes, and health outcomes.

- Data from various sources may be aggregated (i.e., lab data, pharmacy and medical claims, patient characteristics, time of intervention implementation, etc.). However, implementation of the Health Insurance Portability and Accountability Act (HIPAA) could pose additional challenges in the aggregation of data from various sources. Obtaining blanket consent for the integration of patient data may not be overly cumbersome, but one unfortunate result may be the preclusion of some patients unwilling, unable, or otherwise remiss in providing such consent.

These characteristics allow for the evaluation of programs in a "natural setting" as opposed to controlled clinical trials, to provide clinical-effectiveness results used to improve existing programs and processes and, thereby, patient outcomes. Whellan et al..$^{5}$ recently surveyed 25 MCOs on their DM practices. Results showed that DM concepts and framework (a) varied greatly despite similar program goals, (b) were predominantly implemented as periodic telephone calls to patients, and (c) were not typically measured for cost savings to demonstrate program success. The authors made some pertinent suggestions to improve the understanding of DM and its practices. Most important is a need for greater consistency in the types of outcomes evaluated for there to be more effective comparison between programs. Whellan et al. also suggested the need for the development of integrated databases to support assessments of program quality. Although Whellan et al. discussed DM practices of MCOs and other health care systems, the impact of various MCO models (i.e., group model, staff model, etc.) on DM was not discussed. For example, DM effectiveness can vary across plan type and health maintenance organization (HMO) model type due to differences in provider incentives, benefit designs, or patient cost sharing. Additionally, other barriers to the optimal implementation and analysis of program effectiveness include

- accuracy of claims databases and diagnostic coding issues;

- changes in member enrollment and disenrollment;

- capturing of comorbid conditions, risk factors, and disease severity; and

- lack of quality of life (QoL) data and processes of care.

\section{Study Objectives}

While authors previously have reviewed specific interventions to improve DM (i.e., effectiveness of continuing medical education or case management), ${ }^{9,10}$ there has not yet been a published evaluation of intervention programs in managed care populations. The objectives of this literature review were to

- describe DM programs initiated in managed care populations for CHF, hypertension, and hyperlipidemia-CAD;

- summarize the impact of interventions in each disease state; and

- discuss gaps in the literature and suggest future research requirements.

\section{Methods}

\section{Data Source}

An electronic literature search was conducted through December 2002 by using the MEDLINE database of the National Library of Medicine (beginning in 1966), HealthSTAR (beginning in 1975), Cochrane Database of Systematic Reviews (fourth quarter 2002), and International Pharmaceutical Abstracts (beginning in 1970). The search of medical subject headings included: disease state management, disease management, intervention, quality improvement, managed care, health 
maintenance organization, health plan, Medicare, Medicaid, hypertension, congestive heart failure, coronary artery disease, coronary heart disease, hyperlipidemia, lipids, and cholesterol. All subheadings were included. First, article titles and abstracts resulting from the search were reviewed for topic significance, and potential relevant full-text articles (or abstracts where full-text articles were unavailable) were extracted. Pertinent abstracts where full-text articles were not obtainable were excluded from the review. Then, additional relevant citations from reviewed articles (extracted from the electronic search stated above) were obtained.

\section{Article Selection}

All types of study designs were included. Additional inclusion criteria were:

- Interventions or programs were implemented for patient populations in managed care settings (i.e., specific health plans, group practices, HMOs) including Medicare and Medicaid managed care populations.

- While the concept for intervention implementation had to originate from the MCO, implementation was not required to be conducted by the MCO, (i.e., interventions coordinated by primary care providers or contracted vendors were included).

- Management of the following disease states were selected: CHF, hypertension, and hyperlipidemia-CAD.

Studies were excluded if

- interventions were not implemented,

- quantitative results were not reported or the study was only available as an abstract,

- evaluation did not occur within a managed care population, and

- programs were implemented in the veterans population.

\section{Data Synthesis}

All studies that met the inclusion/exclusion criteria were evaluated critically to ensure reporting of relevant information. Study design, type of managed care population, follow-up time frame, population/sample size, intervention components, and outcomes were summarized and evaluated for each article (see Appendix). A descriptive review was undertaken to summarize the effectiveness of each DM program. Studies with rigorous designs (randomized controlled studies) were considered to be of greater value (due to greater reliability/validity and decreased bias) than studies with nonexperimental designs. The literature findings were organized according to disease state and rigor of study design (i.e., randomized controlled studies are presented prior to quasi-experimental studies).

\section{Results}

A majority of the citations were excluded primarily due to interventions not implemented and evaluations conducted in nonmanaged care populations (Table 1). A total of 20 studies

\section{TABLE 1 Summary of Excluded Studies}

\begin{tabular}{l|c|c|c}
\hline Exclusion Criteria & $\begin{array}{c}\text { Congestive Heart } \\
\text { Failure, Total } \\
\text { Citations = 138 } \\
\text { (\% Excluded) }\end{array}$ & $\begin{array}{c}\text { Hypertension, Total } \\
\text { Citations = 72 } \\
\text { (\% Excluded) }\end{array}$ & $\begin{array}{c}\text { Hyperlipidemia- } \\
\text { Coronary Artery } \\
\text { Disease, Total } \\
\text { Citations = 55 } \\
\text { (\% Excluded) }\end{array}$ \\
\hline $\begin{array}{c}\text { Interventions } \\
\text { not implemented }\end{array}$ & $77(56)$ & $46(64)$ & $31(56)$ \\
\hline $\begin{array}{c}\text { Quantitative results } \\
\text { not available or study } \\
\text { in abstract format only }\end{array}$ & $6(4)$ & $2(3)$ & $1(2)$ \\
\hline $\begin{array}{c}\text { Non-managed care } \\
\text { populations }\end{array}$ & $48(35)$ & $15(20)$ & $0(0)$ \\
\hline $\begin{array}{l}\text { Veterans } \\
\text { Administration studies }\end{array}$ & $2(1)$ & $0(0)$ & $17(31)$ \\
\hline
\end{tabular}

meeting the inclusion/exclusion criteria were found for the 3 disease states of interest. A total of 138 literature citations on DM of CHF were found, of which 5 (4\%) met the inclusion criteria. In hypertension, a total of 72 literature citations on DM were found, of which only 9 (13\%) met the inclusion criteria. For DM of hyperlipidemia-CAD, 55 literature citations were found, of which 6 (11\%) met the inclusion criteria (Table 2).

\section{Congestive Heart Failure}

Published studies of DM strategies in CHF among managed care populations were minimal in number and without rigorous study designs because all studies were "before-and-after" comparisons without a control group. Only 2 studies reported findings from intervention programs sponsored by private MCOs, and the remaining 3 reported findings from Medicare- or Medicaid-sponsored programs. A comprehensive DM program (Roglieri et al. ${ }^{11}$ ) targeted the process of follow-up care of CHF and found significant improvements in hospital admission rates and length of stay among 149 commercial members and Medicare HMO recipients with CHF. Relevant program components included (a) weekly "telemonitoring" calls by nurses to assess program enrollee symptom status, with an option for notifying physicians of unstable conditions; (b) posthospitalization follow-up conducted by nurse case managers, including intensive self-management training; and (c) the dissemination of provider educational materials promoting the program and increasing awareness of national clinical treatment guidelines and formulary recommendations.

Only patients enrolled in the program received telemonitoring and posthospitalization follow-up. The same baseline and follow-up in the autumn season was compared with control for seasonal variation. One-year follow-up data on program participants with a primary diagnosis of CHF showed hospital admission rates declined by $83 \%$ (from 80.5 admissions to 13.4 admissions among program participants, $P=0.008$ ) from baseline, the average length of stay went from 7.3 to 8.0 days (not 
(TABLE 2$)$ Summary of Study Characteristics Included for Review

\begin{tabular}{l|c|c|c|c|c|c}
\hline & & \multicolumn{2}{|c|}{ Population } & \multicolumn{2}{c}{ Study Designs } \\
\hline Disease State & $\begin{array}{c}\text { Total No. of } \\
\text { Studies Meeting } \\
\text { Inclusion Criteria }\end{array}$ & $\begin{array}{c}\text { Studies in Medicare/ } \\
\text { Medicaid Population }\end{array}$ & $\begin{array}{c}\text { Traditional MCO } \\
\text { Populations } \\
\text { (i.e., HMO, PPO) }\end{array}$ & $\begin{array}{c}\text { Randomized } \\
\text { Controlled Trials }\end{array}$ & $\begin{array}{c}\text { Pontrolled Studies } \\
\text { Postcomparisons and } \\
\text { Postcomparisons }\end{array}$ \\
\hline CHF & 5 & 3 & 2 & 0 & 0 & 5 \\
\hline Hypertension & 9 & 2 & 7 & 4 & 2 & 3 \\
\hline Hyperlipidemia-CAD & 6 & 1 & 5 & 2 & 3 & 1 \\
\hline
\end{tabular}

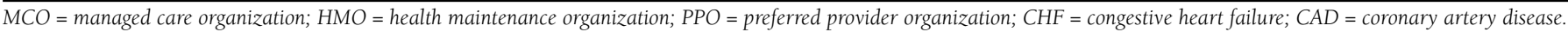

evaluated statistically), and emergency room (ER) visits were reported to be zero. The effectiveness of the program was also assessed for the plan population. Despite an insignificant change in the number of ER visits (from 0.029 to 0.025 visits per 1,000 patients, $P=0.84$ ), the average length of stay declined by 2 days (from 7.6 to 5.6 days, $P=0.2$ ), and the hospital admission rate declined by $63 \%$ (from 0.27 to 0.10 admissions per 1,000 patients, $P=0.00002$ ). The intervention (telemonitoring and postdischarge follow-up of enrollees and provider education) was associated with reductions in hospitalization and length of stay in a managed care population with CHF. Exclusion of patients with lower ejection fractions, a small number of program participants, lack of a control group, and a lack of adjustment for duration of exposure to the intervention program were key limitations of the analysis.

The effect of a nurse case management program, MULTIFIT, was evaluated in 51 patients in a staff-model HMO by West et al. ${ }^{12}$ MULTIFIT (described as a physician-supervised, nursemediated, home-based chronic DM program) promoted the use of optimal doses of heart-failure therapies, daily sodium intake $<2$ grams, and monitoring the signs and symptoms of worsening clinical condition with subsequent follow-up care. Phone calls were used frequently to monitor patients and teach selfmanagement skills (such as self-monitoring of warning symptoms-shortness of breath and sudden weight gain-of heart failure progression requiring medical attention).

The intervention decreased health care utilization (i.e., ER visits and hospitalizations), improved patient functional status, increased the appropriate use of medications, and enhanced lifestyle modifications after 6 months. ER visits declined by $53 \%$ (from 1.5 to 0.7 visits per patient normalized for variable follow-up, $P=0.001$ ), and CHF-related hospitalizations declined by $87 \%$ (from 1.12 to 0.15 per patient per year, $P<0.001)$. The proportion of patients with New York Heart Association (NYHA) class III/IV declined significantly (from $80 \%$ to $50 \%, P=0.007$ ), and average medication doses increased significantly for patients treated with lisinopril (target $=20 \mathrm{mg}$ daily), captopril (target $=150 \mathrm{mg}$ daily), and hydralazine (target $=300 \mathrm{mg}$ daily) postintervention (from $17 \mathrm{mg} /$ day to $23 \mathrm{mg} /$ day for lisinopril, $P<0.001$; from
$67 \mathrm{mg} /$ day to $100 \mathrm{mg} /$ day for captopril, $P=0.04$; and from $140 \mathrm{mg} /$ day to $252 \mathrm{mg} /$ day for hydralazine, $P=0.01$, respectively). Although average doses for captopril and hydralazine were not at target, the overall increase suggests that a greater number of patients achieved target doses. Lastly, self-reports of average sodium intake declined from 3,393 $\mathrm{mg}$ /day to 2,088 $\mathrm{mg} /$ day $(P<0.001)$. In this study, nurse case management of $\mathrm{CHF}$ demonstrated positive outcomes as measured at 6 months of follow-up compared with 6 months prior to program implementation. Although positive outcomes (increased functional status and improvement in medication usage) were reported, the follow-up was for a short period in a small number of patients.

A multidisciplinary DM program (O'Connell et al. ${ }^{13}$ ) primarily in Medicare and Medicaid patients $(\mathrm{n}=35)$ with $\mathrm{CHF}$ not eligible for heart transplant demonstrated improvements in hospitalization and associated costs, use of appropriate medications, and improved clinical outcomes. The program included (a) appropriate drug therapy evaluation conducted by a cardiovascular pharmacist (evaluation based on national CHF treatment guidelines set forth by the Agency for Health Care Policy and Research); (b) intensive education pertaining to diet, exercise, and self-monitoring; and (c) weekly follow-up by cardiologists, nurse practitioners, social workers, pharmacists, a dietitian, and the cardiac rehabilitation team. Participants were stratified by disease severity, those with 2 or more hospital admissions (Group A) versus those referred to the program by their primary care physicians (not necessarily having any hospital admissions [Group B]).

One-year follow-up results showed that compared with baseline, the number of hospital admissions decreased in number from 33 to 3 in Group A and from 9 to 0 in Group B, with a net average savings of $\$ 4,600$ per patient. The use of appropriate drugs (angiotensin-converting enzyme inhibitors [ACEI] and angiotensin receptor blockers [ARB]) increased from 36\% to $71 \%$ in Group A (P value not reported), but did not change in Group B. Significant improvement in NYHA functional class was seen in both Groups A and B $(P<0.001$; refer to the Appendix for the number of patients in each NYHA functional class). The unique feature of this program was its multidisciplinary approach, especially the inclusion of a social worker, which may have led to 
increased access to care and financial assistance, thus contributing to the positive outcomes. Although diet and exercise were part of the educational component and were monitored, results pertaining to these specific end points were not reported. This study suggests that a multidisciplinary approach to managing CHF patients may be effective in reducing hospital admissions and improving medication use in an indigent, CHF population ineligible for heart transplant.

The remaining 2 programs, both Medicare-sponsored interventions described as QI initiatives, showed improvements in appropriate drug use..$^{14,15}$ The first program, aimed at increasing the use of ACEI and/or ARBs during hospitalization (Boer et al. ${ }^{14}$ ) in 244 patients, used a resource tool developed by the Medicare Quality Improvement Organization for Kentucky (Project Handbook), which was based on programmed learning using "programmed texts and/or computers in health education." The Project Handbook was an informational tool kit, including data abstraction and analysis software, for implementing a QI program. Compared with baseline, use of ACEI and/or ARBs increased from $54.1 \%$ to $72.1 \%(P<0.001)$ during 6 months of follow-up. This was compared with statewide benchmarks; the statewide use of ACEI and/or ARBs increased from $59.5 \%$ to $65.4 \%$ during the same follow-up period. The QI program demonstrated an $18 \%$ increase in the number of patients initiated on ACEI or ARBs, and the control benchmark showed a 5.9\% increase (statistical analysis for intervention compared with control not reported). Despite the lack of clarity of the intervention, the simplicity of the program goal allowed for meaningful interpretation of the results. It appeared that the primary intervention component was provider education regarding the use of ACEI/ARBs in CHF. Although the initiation of ACEI/ARBs improved, it is not known if patients were adherent to their medication regimen.

The second Medicare-sponsored QI initiative (Delong et $a . .^{15}$ ) used various interventions aimed at increasing the assessment of left ventricular function and use of ACEIs in 11 hospitals. The interventions ranged from education of health care providers, implementation of critical pathway and care maps, patient or community education, medication protocols, standing orders, and individual physician feedback. The aggregate results of the 11 hospitals in 990 patients during 1.5 years of follow-up indicated that the percent of patients assessed for left ventricular function increased from $53 \%$ to $65 \%(P<0.01)$, and the percentage of patients prescribed an ACEI increased from $54 \%$ to $74 \%(P<0.01)$. The interventions used by each hospital varied and customization was allowed. It was not apparent if one particular intervention component was more effective than another.

\section{Hypertension}

Of the 9 studies in DM of hypertension evaluated, 4 were randomized controlled studies, 2 were controlled studies, and the remaining 3 were before-and-after comparisons. Interventions used to manage hypertension included provider reminder systems and timely feedback, use of ancillary health care staff (such as pharmacists and nurses) to increase monitoring, and the implementation of treatment guidelines to standardize care.

The impact of a pharmacist-managed hypertension clinic compared with usual care in a staff-model HMO was evaluated in a randomized controlled trial by Okamoto et al. ${ }^{16}$ Pharmacist management duties included blood pressure (BP) and lab monitoring with appropriate therapeutic changes and patient education related to lifestyle modifications and drug use. The primary goal of the evaluation was to assess the cost-effectiveness of the intervention; cost measured was total health care costs, and the effect was the amount of BP lowered.

Results after 6 months showed that the average decrease in systolic BP was greater in the intervention group $(\mathrm{n}=164) \mathrm{com}-$ pared with the usual care group ( $\mathrm{n}=166,9.13 \mathrm{~mm} \mathrm{Hg}$ versus $1.32 \mathrm{~mm} \mathrm{Hg}, \mathrm{P}<0.001$ ), and the average decrease in diastolic BP was also greater in the intervention group $(5.14 \mathrm{~mm} \mathrm{Hg}$ versus $1.46 \mathrm{~mm} \mathrm{Hg}, P<0.001)$. Patients in the intervention group were monitored more closely, as reflected by the higher number of average clinic visits per patient (5.25 versus $1.41, P<0.001$ ). The intervention group had a cost-effective ratio of $\$ 27$ per $\mathrm{mm}$ $\mathrm{Hg}$ lowered for systolic BP ( $\$ 48$ per mm Hg for diastolic BP), and the control group had a ratio of $\$ 193$ per mm Hg lowered for systolic BP (\$151 per $\mathrm{mm} \mathrm{Hg}$ for diastolic BP). Costeffectiveness ratios were based on total costs (the sum of emergency room visits, hospitalizations, clinic visits, and drug costs) per $\mathrm{mm} \mathrm{Hg}$ of blood pressure decreased. The authors note that the improved cost-effectiveness was not due to cost reductions but rather to greater effectiveness, i.e., greater reductions in BP. A pharmacist-managed outpatient clinic was reported as cost effective in a hypertensive, managed care population.

The impact of a health education and medication refill reminder program (Sclar et al. ${ }^{17}$ ) on total medical expenditures and utilization was measured in a randomized controlled study of 985 patients. In a staff-model $\mathrm{HMO}$, the intervention $(n=347)$ group received an enrollment kit containing a 30-day supply of atenolol, a hypertension educational newsletter, information on nutrition and lifestyle changes, and written materials outlining the program. Prior to each refill date, patients were contacted via phone to stress the importance of medication adherence. For the following 5 months, the newsletter and a prescription refill reminder were mailed in addition to samples and coupons for health-related items.

Multivariate analysis was used to determine the effect of the intervention on utilization of health services for hypertension. One-year follow-up data demonstrated that the intervention program was associated with significantly lower per capita expenditures ( $\beta=-127.8$ for existing hypertension patients and $\beta=-92.9$ for newly diagnosed hypertension patients, $P \leq 0.001$ for both populations) and lower hospital service utilization (34 hospitalizations in the control group and 3 hospitalizations 
in the experimental group, $P \leq 0.05)$. Only medication costs were increased as a result of the program (an increase of $\$ 117$ per patient, $P \leq 0.001)$. Variables associated statistically $(P \leq 0.05)$ with increased expenditures were medication regimen complexity and age. A patient education program in combination with mailed refill reminders was reportedly effective in reducing total health care cost and utilization. An integral part of the intervention was refill reminders; however, improvement in medication adherence was not reported, although the increased medication costs suggest greater utilization.

The use of an automated surveillance reminder system to improve follow-up care of patients newly identified with elevated diastolic BP $(>100 \mathrm{~mm} \mathrm{Hg})$ was assessed in a randomized controlled study by Barnett et al. ${ }^{18}$ The program, implemented in a group health plan, identified members with documented elevated BP who did not have follow-up within 6 months. These patients were randomized to either receive timely provider feedback for follow-up ( $\mathrm{n}=63$ ) or not receive any reminders $(n=52)$. The intervention was reportedly successful in achieving its intended purpose- the degree to which follow-up was performed (either attempted or accomplished; accomplished defined by a repeat BP measurement). At 12 months, the percentage of patients with attempted or accomplished follow-up was higher in the intervention group compared with the control group ( $84 \%$ versus $25 \%, P<0.01)$. The percentage of patients with attempted or accomplished follow-up at 24 months increased to $98 \%$ in the intervention group and $46 \%$ in the control group $(P<0.01)$. Documentation of a second BP reading was also higher in the intervention group compared with the control group at both 12 and 24 months (49\% versus 31\% at 12 months, $P<0.05 ; 70 \%$ versus $52 \%$ at 24 months, $P<0.05$ ). This intervention, intended to improve the process of care, was unique because it identified and intervened on a necessary process for the management of hypertension. A more robust program would report the additional process of care for instituting therapeutic management (including types of antihypertensives used for treatment) and effective control of diastolic and systolic BP.

Skaer et al. ${ }^{19}$ measured the impact of a pharmacy refill reminder in the Medicaid population in a randomized controlled study. Two types of tools to enhance medication compliance were implemented: mailed refill reminders and unit-of-use packaging (defined as a sequentially numbered 30-day supply inventory tray with easy-access compartments). The control $(\mathrm{n}=78)$ group received standard pharmaceutical care (medication counseling) at the time of medication dispensed. Group 1 $(\mathrm{n}=73)$ received standard care and a refill reminder 10 days prior to refill date via mail, Group $2(n=85)$ received standard care and unit-of-use packaging with each refill request, and Group $3(n=68)$ received standard care and both complianceenhancing tools. One-year follow-up results showed that Groups 1, 2, and 3 had significantly higher medication compli- ance (measured by medication possession ratio [MPR]) relative to the control group (Group $1 \mathrm{MPR}=0.64$, Group $2 \mathrm{MPR}=$ 0.64 , Group $3 \mathrm{MPR}=0.79$, control MPR $=0.56 ; \mathrm{P} \leq 0.05$ ). There was no difference in compliance between Groups 1 and 2, but Group 3 had significantly higher MPR relative to Groups 1 and 2 ( $\mathrm{P} \leq 0.05)$. Despite an increase in drug costs in all groups relative to control, total costs of medical care decreased significantly in Group 3 (decrease of $\$ 20.70$ in Group 1, \$13.66 in Group 2, $\$ 75.28$ in Group 3 [P $\leq 0.05]$ compared with control) primarily due to reductions in hospitalization costs. The authors concluded that refill reminders may be useful for enhancing medication compliance in a Medicaid population. The impact of improved medication compliance on improvement in BP was not assessed.

Of the 2 nonrandomized controlled design studies, one measured the impact of a clinical pharmacist medication monitoring program on the appropriate utilization and costs of antihypertensives, ${ }^{20}$ and the other measured the impact of provider feedback on monitoring and control of high $\mathrm{BP}^{21}$ The continuous monitoring of patient profiles $(n=154)$ by pharmacists (Forstrom et al. ${ }^{20}$ ) increased the cost and appropriate utilization of antihypertensives compared with 172 patients who were not monitored. The intervention was designed to target physicians and was implemented by pharmacists. Based on continuous monitoring, a medication consultation note written by the pharmacist was placed in the medical chart prior to the patient visit, which allowed for physician review immediately prior to the point of care. The intervention resulted in a reduction in the cost of antihypertensive therapy by an average of 5.6 cents per patient per day, a decrease in the percentage of patients on inappropriate doses ( $>50 \mathrm{mg} /$ day) of hydrochlorothiazide (26\% versus $72 \%, P<0.01)$, and a decrease in the use of prazosin $(30 \%$ versus $80 \%, P<0.01)$. A reduction in the use of prazosin was sought due to its high cost at the time and potential for lost efficacy over time. These findings corroborate other evidence that pharmacist-led interventions may be helpful in promoting appropriate pharmacotherapy in Medicaid and HMO patient populations. Only drug costs were reported, and the impact on the cost of other health care resource utilization and BP level was not evaluated.

The second nonrandomized controlled study by Winickoff et al. ${ }^{21}$ measured the effect on hypertension management of feedback to providers. Results at 6 months of follow-up indicated that this intervention, involving concurrent physician feedback on individual patients $(n=1,829)$ and peer comparison performance reports, did not result in any substantive gains in outcomes to the care provided or in greater BP control. The authors hypothesize that the clinical team in the study was already committed to the management of hypertension and aware of national treatment guidelines. Although this result differs from other studies that have found physician feedback reports to be beneficial, the interventions were not identical and 
therefore may not be comparable. . $8,20,22-23^{2}$

The remaining 3 studies were precomparisons and postcomparisons. ${ }^{24-26}$ They encompassed patient education programs and implementation of clinical treatment guidelines. Two of these studies used various patient educational methods to measure the impact on BP and patient QoL. ${ }^{22,24}$ A mixed-model HMO-sponsored program (Casasanta et al..$^{24}$ ) implemented a 2-week interactive patient educational session and provided home BP monitoring machines in conjunction with quarterly newsletters on heart disease to 355 patients. Group educational sessions were provided by different health care professionals and included education on lifestyle modifications, medication use, and disease knowledge. Six months after program implementation, a significantly higher percent of patients achieved BP goal $(<140 / 90 \mathrm{~mm} \mathrm{Hg}$ ) relative to baseline (59\% versus $40 \%$, $P<0.05)$. Lifestyle modifications, such as percentage of patients exercising more than 3 days per week, did not occur after educational sessions. QoL data collected showed mental health and physical health indices improved modestly (improvement of 4\% and $2 \%$ respectively, $P<0.05$ for both end points). The study results suggest that intensive patient education and promotion of self-management skills in hypertension improved BP values. Major study limitations were selection bias due to self-referral, exclusion of participants due to a lack of BP reading, and the inability to determine whether the outcome was the result of education or a change in medication regimen or lifestyle modifications or a combination of all factors.

A similar intervention (Patton et al. ${ }^{25}$ ) was used in a groupmodel HMO where a half-hour educational session led by trained nurses was used to reinforce recommended treatment. In addition, printed educational materials were provided to 107 program participants. Follow-up monitoring and education was provided at 1, 3, 6, and 12 months after the initial session. After 1 year, results showed that BP was significantly reduced ( $P=0.000$ for systolic and $P=0.003$ for diastolic) in program participants. Improvement in systolic BP was significantly associated with increased medication compliance $(P=0.022)$, weight loss $(P=0.001)$, decreased salt use $(P=0.001)$, perceived low stress level $(P=0.047)$, and increased exercise $(P=0.004)$. Improvement in diastolic BP was significantly associated with weight loss $(P=0.004)$, decreased salt use $(P=0.001)$, perceived low stress level $(P=0.002)$, and increased exercise $(P=0.002)$ but not medication compliance. Both studies report that intensive patient education and promotion of self-management techniques may improve the clinical status of hypertensive patients. Participants noncompliant with follow-up care were excluded from the analysis, thus limiting the ability to generalize study findings.

Lastly, the use of clinical guidelines (distributed electronically and in hard copy) along with academic detailing and clinical support by pharmacists was evaluated in a group-model HMO by DiTusa et al. ${ }^{26}$ Achievement of BP goal $(<140 / 90 \mathrm{~mm} \mathrm{Hg}$ in general hypertensives and $<130 / 85 \mathrm{~mm} \mathrm{Hg}$ for diabetics) in 176 patients was related to the number of medications used, medication adherence, comorbidity, lab monitoring, and patient demographic characteristics. Achievement of target BP was significantly associated with ischemic heart disease (odds ratio [OR] 2.79, $P=0.04$ ); drug adherence (OR 2.26, $P=0.01$ ), and treatment with recommended agents $(\mathrm{OR} 3.03, P=0.01)$. Achievement of BP goal was lower among diabetics (OR 0.13, $P<0.01$ ). The use of multiple ( 2 or more) antihypertensive agents was not associated with achievement of BP goal; however, this may be attributed to the lower BP goal among diabetics with hypertension. The small number of diabetic patients evaluated $(n=26)$ and a lack of information regarding their level of diabetes control were potential limitations. The authors recommended that hypertensive diabetics required further interventions and more rigorous management strategies. The dissemination of treatment guidelines helped promote the use of recommended therapies and achievement of BP goal.

\section{Hyperlipidemia}

Five full-text articles presenting study results in hyperlipidemic-CAD, managed care populations were available. The interventions included cholesterol screening and clinical intervention services, dietary educational counseling, automated provider reminder notices for cholesterol remeasurement and treatment of elevated low-density lipoprotein cholesterol (LDL-C), and a pharmacist-managed lipid clinic.

The impact of a Medicare-sponsored program on cholesterol screening was evaluated in a randomized controlled study by Ives et al. ${ }^{27}$ Participants were either enrolled in a hospital-based screening service $(n=1,131)$, a physician-based screening service ( $n=1,347)$, or had no screening $(n=1,225)$. The 2 intervention groups received encouragement to lower cholesterol by lifestyle modifications (i.e., diet and exercise), and if total cholesterol was $\geq 240 \mathrm{mg} / \mathrm{dL}$, then referral for further care (including drug therapy) was made. After 1.5 years, the mean change in total cholesterol for the 3 cohorts was similar (-6.5\% for the hospital group, $-6.6 \%$ for the physician group, and $-5.7 \%$ for the control group). After controlling for lipid-lowering drug use, total cholesterol lowering was similar in the 3 cohorts. The hospital-based cohort had a significantly higher number of provider visits per patient compared with the provider-based cohort (4.2 versus 3.4 , respectively; $P<0.001$ ). Whether or not the hospital-based cohort had more comorbid conditions and therefore more visits was not known. The effectiveness of this program was questionable. The lack of clarity in the description of the intervention and outcomes measured made it difficult to assess the effectiveness and clinical implications of this program. Eligible patients were volunteers aged 65 to 79 years, and findings were limited to this subpopulation.

The impact of a nurse case management program (DeBusk et al. ${ }^{28}$ ) on coronary risk modification in a staff-model HMO was 
assessed in a randomized controlled study. Case management encompassed consultation with other health care providers to administer comprehensive care in smoking cessation, dietary counseling, home-based exercise training program, and drug therapy, when necessary. After 1 year of follow-up, smoking cessation was observed in $70 \%$ of the intervention patients ( $n=293)$ compared with $53 \%$ in the usual care group $(n=292)$, $P=0.03$. The percentage of patients achieving low-density lipoprotein cholesterol (LDL-C) $<130 \mathrm{mg} / \mathrm{dL}$ was $83 \%$ in the intervention group and 50\% in the control group, and the percentage of patients achieving LDL-C $<100 \mathrm{mg} / \mathrm{dL}$ was also higher in the intervention group (42\% versus 15\%). Greater mean reductions in LDL-C was associated with the intervention $(\beta=-0.65, P<0.001)$. Significant differences in high-density lipoprotein cholesterol (HDL-C) and triglycerides were not observed. More patients in the intervention group received drug therapy (90\% versus $21 \%$ ), which would explain the significant difference in mean LDL-C reduction between the 2 groups. Participation in home-based exercise training was observed in $63 \%$ of the intervention patients and only 5\% in patients receiving usual care. The results indicate that comprehensive case management may help modify cardiovascular risk factors; however, this evaluation was limited to patients previously hospitalized for acute myocardial infarction.

The effect of patient counseling by health care professionals on dietary knowledge (Schectman et al. ${ }^{29}$ ) was assessed in 325 patients in a group-model HMO. The intervention clinic contained AHA dietary educational pamphlets for physicians/ nurses to use when providing dietary counseling. Results of the linear regression analysis (after 18 months of follow-up) indicated that dietary education did not impact patient dietary knowledge. Predictors of patient dietary knowledge were educational level $(P=0.03)$, level of baseline dietary knowledge $(P=0.005)$, and patient-reported dietary changes $(P=0.0003)$. Clinical markers such as lipid measurements were not assessed. While dietary education was not associated with knowledge, any conclusions drawn from this study may be tenuous, as details regarding the length and the extent of the counseling sessions were not reported.

Two studies evaluated the impact of an automated physician reminder system. ${ }^{22,23}$ In a staff-model HMO, the effect of automated physician reminders on lipid levels of 7,001 patients was assessed before and after the reminders were initiated by Khoury et al. ${ }^{22}$ Other elements of the intervention were individual physician and peer-performance reports and quarterly patient (diagnosed with CAD and their respective LDL-C levels) lists. At 18 months of follow-up, the percentage of patients without documented LDL-C measurements decreased from $30 \%$ to $18 \%(P<0.001)$, and the percentage attaining an LDL-C goal of $\leq 100 \mathrm{mg} / \mathrm{dL}$ increased from $10 \%$ to $27 \%(P<0.001)$. Whether or not LDL-C goal was achieved through changes in medication regimen or through life-style modification was not evaluated. A targeted physician reminder system, along with individual and group performance feedback, demonstrated positive clinical outcomes.

The above intervention ${ }^{22}$ was used in the same staff-model HMO for 7,066 patients to increase the use of aspirin and promote the lowering of LDL-C to $<100 \mathrm{mg} / \mathrm{dL}$ in CAD patients and to increase the use of ACEI in CHF patients (Khoury et $\mathrm{al}^{23}$ ). Additional components of the intervention included financial incentive for providers and quarterly "report cards" comparing individual provider performance with group performance. Once again, the same intervention was effective in achieving the primary end points. The use of aspirin increased from $56 \%$ to $81 \%$, and the use of ACEI increased from 54\% to $67 \%$ after 2 years of follow-up ( $P<0.001$ for both end points). Patient attainment of LDL-C goal (measured 7 months postintervention) increased from $10.3 \%$ to $18.9 \%(P<0.001)$. A secondary end point, percentage of patients not screened for LDL-C within the past 2 years, decreased from 30.3\% to 24.2\% $(P<0.001)$. Whether or not aspirin use and attainment of LDL-C goal led to reductions in myocardial infarction or the use of ACEI improved NYHA function class was not evaluated. The unique characteristics of this program included targeting CAD and CHF patients simultaneously and the use of financial incentives for providers if improvement in care was demonstrated.

A staff-model HMO reported the impact of a pharmacist managed lipid clinic (Merenich et $\mathrm{al}^{30}{ }^{30}$ ) on 1,716 patients. Pharmacists were responsible for lipid management through appropriate laboratory monitoring, adjustment of lipid-lowering medications, and periodic follow-up clinic visits. One-year follow-up analysis showed the percentage of patients with LDL-C $\leq 130 \mathrm{mg} / \mathrm{dL}$ increased from 58\% to 84\% after implementation of the pharmacist-managed lipid clinic, the percentage of patients with LDL-C $\leq 100 \mathrm{mg} / \mathrm{dL}$ increased from $22 \%$ to $48 \%$, the use of beta-blockers post-myocardial infarction increased from $85 \%$ to $92 \%$, and the percentage of patients on aspirin or other antiplatelet therapy increased from $90 \%$ to $97 \%$. The results of statistical analyses were not reported. Although the pharmacist-managed lipid clinic improved LDL-C and increased the use of appropriate drug therapy, it could not be ascertained whether these improvements led to reductions in morbidity and mortality.

\section{Discussion}

\section{Summary of Key Findings}

This qualitative review did not attempt to quantify the findings. The review was intended to provide some idea of the availability of quantitative analysis conducted for CVD interventions specifically in managed care populations. Although the prevalence of CVD intervention strategies in managed care populations is increasing, ${ }^{5}$ effectiveness analyses in the scientific literature are uncommon. However, the available results suggest that a variety of interventions demonstrate some 
effectiveness in improving outcomes to the 3 disease states that were the subject of this review. Types of interventions that demonstrated effectiveness included case management, physician reminders and feedback, pharmacist-managed clinics, patient education, and development of self-management skills.

Published studies of CHF management typically involved multifaceted programs, which included multiple health care professionals, patient and physician education, intensive drug therapy, emphasis on lifestyle modifications, and close monitoring. Specifically, effective management strategies for $\mathrm{CHF}$ included case management and physician education with an emphasis on close patient monitoring. The high incidence of hospitalization and ER visits associated with $\mathrm{CHF}$ warrant close follow-up. In contrast, hypertension and hyperlipidemia-CAD may be silent diseases in the initial stages and not result in frequent use of health care services. Chronic outpatient management and follow-up along with development of selfmanagement skills appeared to work well in these 2 conditions. For example, pharmacist-led management techniques and use of automated provider notices and intensive patient education demonstrated effectiveness in hypertension. Additionally, effective interventions reported in hyperlipidemia-CAD populations also included pharmacist-led management strategies and automated provider reminders. The only evaluation of case management, ${ }^{28}$ specifically in the care of hospitalized CAD patients, was reportedly effective.

Whereas all the published CHF intervention programs appeared to be successful, 3 studies of hypertension and hyperlipidemia DM interventions were unsuccessful. ${ }^{21,27,29}$ Winickoff et al. ${ }^{21}$ showed that physician feedback did not improve clinical outcomes, contrary to the results reported in other studies. . $^{1820,22-23}$ The success of DM programs depended on provider and patient acceptance. ${ }^{31}$ Although providers acted on reminder notices, it was not always clear that provider action translated into patient compliance, perhaps compromising program success. Similarly, Ives et al. ${ }^{27}$ showed that preventive cardiovascular care for Medicare patients did not lower cholesterol; selection bias was a possible factor because study participation was voluntary. As a result, control patients were most likely motivated individuals who were concerned with their health, perhaps accounting for the absence of a difference in cholesterol reduction between control and program participants. Lastly, Schectman et al. ${ }^{29}$ showed that dietary counseling did not increase patient knowledge, which was actually associated with baseline educational level. Clinical parameters were not assessed, and whether or not the counseling showed improvements in cholesterol was not known. Appropriate end point measurement affected the success of the DM program. ${ }^{5}$ Bias against publishing studies of programs that do not show significant results probably accounts for the small number of articles that describe ineffective DM programs.

\section{Shortcomings in Disease Management Program Evaluations in the Literature}

A lack of rigorous study designs was a major shortcoming. Most of the evaluations were before-and-after comparisons, without a control group. A lack of control group and randomization threatens internal validity of studies, including the inability to account for the phenomenon of "regression to the mean." For example, when patients with extremely high LDL-C levels are selected for DM programs, their remeasurement LDL-C levels are more likely to regress to the population mean. The absence of a control group can thereby lead to an erroneous conclusion that the intervention program effectively lowered LDL-C. However, this effect is less troublesome when outcomes are measured continuously over time, and continuous measurements are necessary to more reliably demonstrate improvements resulting from the intervention.

Another difficulty in evaluating the studies was the lack of standard criteria in determining the effectiveness of DM programs due to variation in outcomes measured and patientselection criteria. Outcomes measured primarily entailed a combination of impact on health care resource utilization (i.e., hospitalizations, office visits, ER visits, drug utilization patterns, etc. [12 studies]), clinical markers (9 studies), cost or cost-effectiveness (4 studies), and functional status or QoL (3 studies). Since different outcomes were measured, effectiveness across programs was not comparable. Three types of outcomes may be assessed for a given intervention program: clinical, economic, and humanistic (e.g., QoL and satisfaction with care), all of which are important in managed care. ${ }^{31}$ Barriers for assessment of humanistic outcomes include difficulty in accessing QoL data that may require members to complete lengthy questionnaires and the need to choose a proper instrument to detect the changes in QoL as a result of program interventions. ${ }^{3,7}$ An ideal evaluation of intervention strategies should include measurements of all 3 types of outcomes. This would allow for effectiveness comparison across different interventions.

Variation in patient-selection criteria also led to difficulties in determining the effectiveness of DM programs. Either the entire disease population was included or the intervention targeted poorly managed patients or the most severe patients (i.e., risk stratification). Intervention tools varied depending on the targeting strategy. For example, the sickest patients were managed more closely and frequently, often on a one-on-one basis by nurse case managers (which was the case for CHF but not for hypertension or hyperlipidemia). Since populations in various risk categories cannot be compared, appropriate control groups are necessary to ensure comparisons across groups with similar disease severity. Sicker patients (those with NYHA class III/ IV heart failure and prior myocardial infarction or established CAD) are more costly to MCOs. Stratification of sickest patients followed by appropriate intensive management strategies are key factors for cost-effective DM programs. The transparency in the 
stratification process can allow other organizations to adopt similar cost-efficient DM strategies.

The different types of managed care populations studied make it difficult to generalize intervention effectiveness across all managed care populations. Despite the common principles shared by MCOs, the variation in organization, incentives, and delivery of care may contribute to the effectiveness, or lack thereof, of certain interventions. For example, providers in MCOs that are not staff- or group-model HMOs contract with multiple payers, and there may not be sufficient patient volume or financial influence with individual physicians for a given MCO to affect provider behavior in a systematic manner in a DM program. Similarly, the demographic variation in Medicare/Medicaid versus commercial health plans can significantly impact interventions designed to target patient behaviors, e.g., when an elderly Medicare population represents higher severity of disease with multiple comorbid conditions that may represent a more-difficult-to-treat population. The Medicaid population, with lower economic status, is sensitive to cost sharing and may not respond to DM strategies that lead to increased patient costs (i.e., copayments with frequent office visits). The commercial population, in contrast, usually represents younger, healthier patients in whom DM interventions may have minimal impact given their relatively good health status. Studying the same intervention program in different types of MCO populations can bridge this gap.

Much of the literature examined in this review reported results from studies in staff and group HMO settings. While alternative managed care models (i.e., network, IPA, point-ofservice, PPO, mixed model, and others) may pose additional challenges for effective DM, it is among their patient populations where the most substantive gains in clinical and economic outcomes can be secured. First, a far greater number of the insured are enrolled in one of these alternative MCO structures. Secondly, the fact that their care is managed to at least some degree would suggest an environment ripe for collaboration between insurers, employers, and enrollees. Most employers have an interest in the health and well-being of employees, partly out of humanistic concerns but also from recognition of the potential for greater productivity and employee retention. Many of the studies reviewed here, particularly those reporting limited utility in hypertension and hyperlipidemia management, were conducted nearly 2 decades ago. The advent of electronic tools, including automated reminders for patients and caregivers, may contribute to different outcomes if these earlier studies were conducted today.

The studies reviewed demonstrated a lack of uniformity in step-by-step descriptions of DM program components, hindering comparison of interventions across disease states and various settings. For example, a recent survey indicated that the primary component of DM programs was periodic telephone calls where all types of personnel primary care physicians, nurse case managers, specialists, and pharmacists-were involved in the delivery of care. ${ }^{5}$ However, results of this survey could not be used as a benchmark for evaluating the published studies since the interventions were often not described in sufficient detail.

The limited published literature evaluating CVD management strategies in managed care settings made it difficult to determine the best methods for managing large patient populations. Whellan et al. ${ }^{5}$ indicated that $44 \%$ of MCOs surveyed had DM interventions for CHF and another 24\% had interventions designed for cardiac prevention. Despite the growing number of CVD management interventions and QI programs, published data of program outcomes were limited. Some possible reasons may be patient confidentiality, unwillingness to share information with competitors, unwillingness to publish analyses demonstrating poor outcomes, and a lack of resources to conduct evaluations sufficiently rigorous for publication.

Thus, while DM strategies appear to be useful for improving health, better agreement may be required in describing processes for their implementation. Second, MCOs must become more diligent and methodical in measuring cost savings that derive from DM programs. Third, there is a need for standardization in the methods researchers use to quantify the clinical, servicehumanistic, and cost outcomes of these programs.

\section{Future Research}

Many DM programs involved multiple interventions, and most studies did not measure the impact of individual interventions. The identification of effective intervention components can lead to greater efficiencies in DM. Also underdeveloped are optimal methods for targeting patients by risk stratification and the use of control groups in DM program evaluation. Further research is needed about specific DM interventions in patient populations that are well defined in key variables that include disease severity and number and type of comorbid conditions.

Long-term risk of complications resulting from CVD should be considered and measured as an outcome. Lack of continuous enrollment makes it difficult to measure long-term outcomes such as mortality. Whether or not DM interventions decrease mortality in chronic conditions will require considerable research employing longitudinal designs extended over a number of years.

\section{Conclusion}

There is great variation in the type of published CVD management programs conducted in managed care populations. A majority of the interventions showed some type of improvement in the measured outcomes. More intensive, multifaceted management strategies (such as close monitoring conducted by case managers) were more prevalent and appropriate for CHF, a disease that can transform from a chronic state to an acute state quickly if not managed closely. Hypertension and hyperlipi- 
demia, chronic conditions that are typically asymptomatic in the early stages, were found to be effectively managed in the outpatient setting (e.g., through development of patient selfmanagement skills and intermittent follow-up) with or without employing intensive monitoring interventions.

\section{ACKNOWLEDGMENTS}

The author acknowledges the assistance of Winnie Yu, PharmD, BCPS; Tara Cockerham, PharmD; and Krista Yokoyama, PharmD, in the development of this paper.

\section{DISCLOSURES}

No outside funding supported this study. Author Sheta Ara discloses no bias or conflict of interest.

\section{REFERENCES}

1. American Heart Association. 2002 heart and stroke statistical update. Available at: http://www.americanheart.org. Accessed December 17, 2002.

2. Joint National Committee on Prevention, Detection, Evaluation, and Treatment of High Blood Pressure. The Sixth Report of the Joint National Committee on Prevention, Detection, and Evaluation, and Treatment of High Blood Pressure. Arch Intern Med. 1997;137:2413-38.

3. Epstein RS, Sherwood LM. From outcomes research to disease management: a guide for the perplexed. Ann Intern Med. 1996;124:832-37.

4. Disease Management Association of America. Definition of disease management. Available at: http://www.dmaa.org/definition.html. Accessed December 17, 2002.

5. Whellan DJ, Cohen EJ, Matchar DB, et al. Disease management in health care organizations: results of in-depth interviews with disease management decision makers. Am J Manag Care. 2002;8:633-41.

6. The Henry J. Kaiser Family Foundation. Trends and indicators in the changing health care marketplace. 2002 chartbook. Available at:

http://www.kff.org. Accessed December 17, 2002.

7. The CDC Diabetes in Managed Care Work Group. Exploring and expanding the research agenda for diabetes in managed care: a report of a Centers for Disease Control and Prevention managed care workshop. Diabetes Care. 1999;22(10):1734-38

8. Bodenheimer T. The American health care system-the movement for improved quality in health care. N Engl J Med. 1999;340(6):488-92.

9. Davis DD, Thomson MA, Oxman AD, et al. Changing physician performance. A systematic review of the effect of continuing medical education strategies. JAMA. 1995;274(9):700-05.

10. Norris SL, Nichols PY, Caspersen CJ, et al. The effectiveness of disease and case management for people with diabetes. A systematic review. Am J Prev Med. 2002;22(4S):15-38.

11. Roglieri JL, Futterman R, McDonough KL, et al. Disease management interventions to improve outcomes in congestive heart failure. Am J Manag Care. 1997;3:1831-39.

12. West JA, Miller NH, Parker KM, et al. A comprehensive management system for health failure improves clinical outcomes and reduces medical resource utilization. Am J Cardiol. 1997;79(1):58-63.
13. O'Connell AM, Crawford MH, Abrams J. Heart failure disease management in an indigent population. Am Heart J. 2001;141(2):254-58.

14. Boer HR, Pritchard C, Okpokho NA, et al. The use of ACE inhibitors in the treatment of heart failure in Kentucky Medicare beneficiaries: a quality improvement project. J Kentucky Med Assoc. 2002;100(8):317-22.

15. DeLong JF, Allman RM, Sherrill RG, et al. A congestive heart failure project with measured improvements in care. Eval Health Prof. 1998;21(4):472-86.

16. Okamoto MP, Nakahiro RK. Pharmacoeconomic evaluation of a pharmacist-managed hypertension clinic. Pharmacotherapy. 2001;21(11):1337-44.

17. Sclar DA, Skaer TL, Chin A, et al. Effect of health education on the utilization of HMO services: a prospective trial among patients with hypertension. Primary Cardiol. 1992;8(suppl):30-35.

18. Barnett GO, Winickoff RN, Morgan MM, et al. A computer-based monitoring system for follow-up of elevated blood pressure. Med Care. 1983;21(4): 400-09.

19. Skaer TL, Sclar DA, Markowski DJ, et al. Effect of value-added utilities on prescription refill compliance and health care expenditures for hypertension. J Hum Hypertens. 1993;7:515-18.

20. Forstrom MJ, Ried LD, Stergachis AS, et al. Effect of a clinical pharmacist program on the cost of hypertension treatment in an HMO family practice clinic. DICP, Ann Pharmacother. 1990;24:304-08.

21. Winickoff RN, Wilner S, Neisuler R, et al. Limitations of provider interventions in hypertension quality assurance. Am J Public Health. 1985;75(1):43-46.

22. Khoury AT, Wan GJ, Niedermaier ON, et al. Improved cholesterol management in coronary heart disease patients enrolled in an HMO.J Health Care Qual. 2001;23(2):29-33.

23. Khoury AT. A computer-generated reminder program to reduce cardiac morbidity and mortality. Formulary. 1997;(32):1241-44.

24. Casasanta L, Patel S. Outcomes of an educational component of a disease management program for hypertension. Manag Care Interface. 1999;70-73.

25. Patton K, Meyers J, Lewis BE. Enhancement of compliance among patients with hypertension. Am J Manag Care. 1997;3:1693-98.

26. DiTusa L, Luzier AB, Jarosz DE, et al. Treatment of hypertension in a managed care setting. Am J Manag Care. 2001;7:520-24.

27. Ives DG, Kuller LH, Traven ND. Use and outcomes of a cholesterol-lowering intervention for rural elderly subjects. Am J Prev Med. 1993;9(5):274-81.

28. DeBusk RF, Miller NH, Superko RH, et al. A case-management system for coronary risk factor modification after acute myocardial infarction. Ann Intern Med. 1994;120(9):721-29.

29. Schectman JM, Stoy DB, Elinsky EG. Association between physician counseling for hypercholesterolemia and patient dietary knowledge. Am J Prev Med. 1994;10(3): 136-39.

30. Merenich JA, Lousberg TR, Brennan SH, et al. Optimizing treatment of dyslipidemia in patients with coronary artery disease in the managed-care environment (the Rocky Mountain Kaiser Permanente experience). Am J Cardiol. 2000;85(3A):36A-42A.

31. Welch PW, Bergsten C, Cutler C, et al. Disease management practices of health plans. Am J Manag Care. 2002;8:353-61. 
APPENDIX Summary of Evidence-Cardiovascular Disease Management Strategies in Managed Care Populations

\begin{tabular}{|c|c|c|c|c|c|c|}
\hline Study & Design & $\begin{array}{c}\text { Population / } \\
\text { Setting }\end{array}$ & $\begin{array}{l}\text { Evaluation } \\
\text { Time Frame } \\
\text { and Study } \\
\text { Sample (N) }\end{array}$ & $\begin{array}{l}\text { Relevant } \\
\text { Patient- } \\
\text { Selection } \\
\text { Criteria }\end{array}$ & Intervention Description & Outcomes Measured* \\
\hline \multicolumn{7}{|c|}{ CONGESTIVE HEART FAILURE } \\
\hline Roglieri ${ }^{11}$ & $\begin{array}{l}\text { Before- } \\
\text { and-after } \\
\text { comparison }\end{array}$ & $\begin{array}{l}\text { Commercial } \\
\text { and } \\
\text { Medicare } \\
\text { HMO }\end{array}$ & $\begin{array}{l}1 \text { year } \\
\mathrm{N}=149 \\
\text { program } \\
\text { participants }\end{array}$ & $\begin{array}{l}\text { Heart failure } \\
\text { patients were } \\
\text { referred to the } \\
\text { program by their } \\
\text { physician, } \\
\text { enrolled through } \\
\text { a review of } \\
\text { claims, or } \\
\text { referred by a } \\
\text { case manager } \\
\text { after hospital } \\
\text { discharge related } \\
\text { to CHF. }\end{array}$ & $\begin{array}{l}\text { Comprehensive CHF DM } \\
\text { program with } 3 \text { primary } \\
\text { components: } \\
\text { - Telemonitoring. Weekly } \\
\text { phone calls to the patients } \\
\text { were made and an automated } \\
\text { health questionnaire was } \\
\text { administered by nurses. } \\
\text { Questionnaire results were } \\
\text { provided to physicians and } \\
\text { follow-up care was provided } \\
\text { as needed. Based on } \\
\text { questionnaire findings, } \\
\text { educational materials (nutrition, } \\
\text { medication compliance or } \\
\text { exercise and more) were } \\
\text { mailed to the patient. } \\
\text { - Posthospitalization follow-up. } \\
\text { A nurse visited the patient at } \\
\text { home, where CHF education } \\
\text { was provided and self- } \\
\text { management skills taught. } \\
\text { - Provider education. Mailings } \\
\text { and phone calls were made to } \\
\text { providers to increase } \\
\text { awareness of program, } \\
\text { treatment guidelines, and } \\
\text { formulary recommendations. }\end{array}$ & 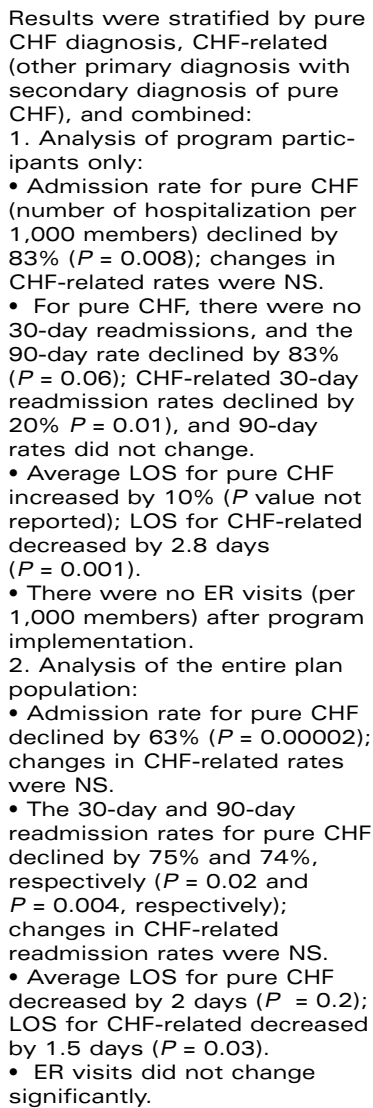 \\
\hline
\end{tabular}

West $^{12} \quad$ Before- $\quad$ Staff-model 6 months Heart failure MULTIFIT, a physician-super-
and-after HMO patients were vised, nurse-mediated, homecomparison $\quad \mathrm{N}=51$ referred to the program by primary care physicians or cardiologists or related to $\mathrm{CHF}$ occurred. based chronic DM program, focused on systematic treatment practices with the follow ing 3 end points:

- promote the optimal doses of ACEI or nitrates based on national clinical guidelines - promote daily sodium intake of <2gm;

- monitor for signs/symptoms of worsening heart failure with subsequent follow-up care

Upon enrollment, nurses used standard forms to record clinical information and functional status of patients. On initial visits, patients were educated on their disease state, sodium restriction and state, sodium restriction and
drug therapy, warning signs of worsening conditions, and behavioral techniques/ interventions to increase compliance with dietary and drug therapy. Subsequent phone monitoring was done. A computerized database was used for tracking purposes. Weekly monitoring phone calls were made for 6 weeks
Medical resource utilization: - Medical visits declined by $23 \%(P=0.03)$ after program implementation.

- Cardiology visits declined by $31 \%(P=0.02)$

- ER visits declined by $53 \%$ $(P=0.001)$

- Heart failure hospitalization (per year) declined by $87 \%$ ( $P=0.0001$ ).

Patient functional status: - The proportion of patients in NYHA class III/IV declined $(P=0.007)$.

- Duke Activity Status Index improved from 24.9 to 28 $(P<0.01)$.

- Physical component of the SF-36 improved from 35.2 to $40.6(P=0.04)$

- Self-reported weight declined from an average of $180 \mathrm{lbs}$. per patient to 177 lbs. (NS).

Medication use and dietary changes:

- Average doses for lisinopril (target $=20 \mathrm{mg}$ daily), captopri (target $=150 \mathrm{mg}$ daily $)$. and hydralazine (target $=300 \mathrm{mg}$ daily) increased significantly (from 17 to $23 \mathrm{mg} /$ day.
Major Limitationst

Group excluded from analysis had an average ejection fraction lower than the included group.

Only a small group of program participants were evaluated.

Adjustments for duration of exposure to the CHF program were not made.

Very small number of patients were evaluated.

Patient improvement beyond 6 months cannot be determined due to the short follow-up.

Patients who could not communicate via telephone and who had dementia, psychiatric diseases, or substance abuse were excluded.

\section{ns}




\begin{tabular}{cccc}
\hline & Evaluation & $\begin{array}{c}\text { Relevant } \\
\text { Time Frame } \\
\text { and Study } \\
\text { Satient- } \\
\text { Selection } \\
\text { Criteria }\end{array}$ \\
\hline
\end{tabular}

Intervention Description

(followed by calls at week 8 , $10,16,20,24)$; an ER or hos pitalization visit prompted another 6 weeks of weekly calls.

\begin{tabular}{llll}
\hline $\mathrm{O}^{\prime}$ Connell & $\begin{array}{l}\text { Before- } \\
\text { and-after } \\
\text { comparison }\end{array}$ & $\begin{array}{l}\text { Medicare } \\
\text { and }\end{array}$ & 1 year \\
& $\mathrm{N}=35$
\end{tabular}

Medicare

\section{Enrollees were categorized into 2 groups: Group A contained patients with 2 or more hospital readmissions, and Group B contained patients referred by primary care physicians or from the partici- pating hospital team (not neces- sarily havin \\ hospital admissions).}

Multidisciplinary DM program that included a systematic approach to - drug therapy; - intensive one-on-one patient education on diet, exercise. self-monitoring, and regular follow-up care; and

- need for social services and other support.

The team was composed of cardiologists, nurse practitioners, social workers. pharmacists with training in pharmacists with training cardiovascular diseases,
dietitians, and the cardiac rehabilitation group. Enrollees were monitored in the ambulatory care clinic or via weekly phone contact by team members. Intensive patient education was administered, education was administered, and medication consultation was provided and continuously modified. Individualized care for all other conditions was provided when necessary.

The intervention was a Ql program to improve hospital care gram to improve hospital care heart failure patients admitted by the participating hospita were eligible.
Excel (HCE), the Medicare

Quality Improvement Organ-

ization for Kentucky, developed the program by creating a Project Handbook, which was given to each institution given to each institution treating Medicare heart failure
patients and willing to partici-
pate in the program. The handpate in the program. The han book contained all pertinent information necessary to implement the program and software required for data abstraction/analysis. All participating institutions were sent a copy of their specific baseline data and state-wide benchmarks.

The Ql program was intended to increase the use of ACE and/or ARB in hospitalized CHF patients. Each hospital's use of ACEI/ARB upon discharge was analyzed. Hospitals with low performance received support from a clinical coordinator (contracted by HCE) for program improvement.
Major

Outcomes Measured*

Limitations

$P=0.0004$; from 67 to $100 \mathrm{mg} /$

day, $P=0.04$, and from 140 to $252 \mathrm{mg} /$ day, $P=0.01$, respec-

tively); isosorbide dinitrate

(target $=160 \mathrm{mg}$ daily) and (target $=160 \mathrm{mg}$ daily) $\mathrm{and}$
furosemide (target $=80 \mathrm{mg}$ furosemide (target $=80 \mathrm{mg}$
daily) average doses did not change significantly (from 75 to $91 \mathrm{mg} /$ day, $P=0.07$ and from 76 to $67 \mathrm{mg} /$ day, $P=0.3$, respectively).

- Self-reported sodium intake declined from 3,393 to 2,088 $\mathrm{mg} /$ day $(P=0.0001)$.

NYHA functional class:

- Group A: 4 patients changed from class IV to II/III, and 9 patients changed from III to II $(P<0.001)$

- Group B: 10 patients changed from class III to II, 9 changed from II to I $(P<0.001)$.

Medication use:

- Group A: the percentage of patients on ACEI or ARBs increased from $36 \%$ to $71 \%$. - Group B: the percentage of patients on ACE or ARB did not change.

Hospital admissions:

- Group A: number of hospital admissions decreased from 33 to 3 (respective costs were

$\$ 183,698.00$ and $\$ 16,700.00$ )

- Group B: number of hospital admissions changed from 9 to 0 (respective costs were

$\$ 50,100.00$ and $\$ 0$ ).

- Net savings from hospital and clinic charges were $\$ 162,00$ per year or $\$ 4,600$ per patient.

The rate of $\mathrm{ACEI}$ use (number of discharged heart failure patients given an ACEl during hospitalization divided by the number of all heart failure patients discharged) improved from $54.1 \%$ to $66.0 \%$

$(P=0.019)$.

The rate of either ACEI or ARB use improved from $54.1 \%$ to $72.1 \%(P<0.001)$.

In contrast, the statewide use of ACEI decreased from $59.5 \%$ to $55.1 \%$, and the use of $A C E$ Results indicating changes in diet and exercise were not reported.

Very small number of patients were evaluated.

Results cannot be extrapolated to severe patients eligible for heart transplant.

\section{Intervention}

description lacked clarity.

Medication adherence was not assessed.

The effect of medication initiation on functional status and symptom improvement was not measured. 
APPENDIX Summary of Evidence-Cardiovascular Disease Management Strategies in Managed Care Populations

\begin{tabular}{|c|c|c|c|c|c|}
\hline Study & Design & $\begin{array}{c}\text { Population / } \\
\text { Setting }\end{array}$ & $\begin{array}{c}\text { Evaluation } \\
\text { Time Frame } \\
\text { and Study } \\
\text { Sample (N) }\end{array}$ & $\begin{array}{c}\text { Relevant } \\
\text { Patient- } \\
\text { Selection } \\
\text { Criteria } \\
\end{array}$ & Intervention Description \\
\hline Delong $^{15}$ & $\begin{array}{l}\text { Before- } \\
\text { and-after } \\
\text { comparison }\end{array}$ & Medicare & $\begin{array}{l}1.5 \text { years } \\
\mathrm{N}=990 \\
\text { (outcome 1), } \\
608 \\
\text { (outcome 2) }\end{array}$ & $\begin{array}{l}\text { Hospitalized } \\
\text { patients with a } \\
\text { diagnosis of } \mathrm{CHF} \\
\text { or signs and } \\
\text { symptoms } \\
\text { suggesting CHF } \\
\text { were eligible. }\end{array}$ & $\begin{array}{l}\text { The interventions were based } \\
\text { on national clinical guideline } \\
\text { concepts. The interventions } \\
\text { included education of health } \\
\text { care providers, critical pathway } \\
\text { and care maps, patient or } \\
\text { community education, medi- } \\
\text { cation protocols, standing } \\
\text { orders, or individual physician } \\
\text { feedback. Each participating } \\
\text { hospital chose specific, } \\
\text { customized interventions to } \\
\text { implement. }\end{array}$ \\
\hline
\end{tabular}

Outcomes Measured* Outcome 1: the percentage of patients with left ventricular function tests increased from $53 \%$ to $65 \%(P<0.01)$.

Outcome 2: the percentage of patients receiving $A C E$ increased from $54 \%$ to $74 \%$ $(P<0.01)$
Major Limitationst Intervention components varied within each hospital.

The hospital setting variedsmall rural, small urban, medium urban, medium urban, and large
urban hospitalsand its impact on outcomes was unknown.

Impact of ACE treatment on functional status and improvement of symptoms was not evaluated.

\section{HYPERTENSION}

Okamoto Randomized, Staff-model 16 comparative HMO study

\begin{tabular}{|c|c|}
\hline $\begin{array}{l}6 \text { months } \\
N=166(\mathrm{C}) \\
164(\mathrm{I})\end{array}$ & $\begin{array}{l}\text { Patients were } \\
\text { included if they } \\
\text { were aged } 18 \\
\text { years, had a } \\
\text { diagnosis of } \\
\text { essential } \\
\text { hypertension, } \\
\text { filled prescrip- } \\
\text { tions at the McO } \\
\text { pharmacies, } \\
\text { had } 1 \text { year } \\
\text { enrollment in } \\
\text { the MCO, and } \\
\text { were taking one } \\
\text { of the targeted } \\
\text { prescription } \\
\text { antihypertensive } \\
\text { drugs (nifedipine, } \\
\text { verapamil, } \\
\text { captopril, } \\
\text { diltiazem, } \\
\text { clonidine, } \\
\text { terazosin, } \\
\text { propranolol, or } \\
\text { lisinopril) or } \\
\text { taking at least } \\
3 \text { antihyperten- } \\
\text { sive agents. }\end{array}$ \\
\hline
\end{tabular}

A pharmacist-managed care clinic was compared with a general medicine clinic. The clinical pharmacist managed - blood pressure monitoring and appropriate therapeutic changes.

- medication counseling and monitoring of labs, and - Nonpharmacologic education for controlling blood pressure.

The control group received care from their primary care providers in the usual manner.

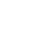
hypertension ambulatory

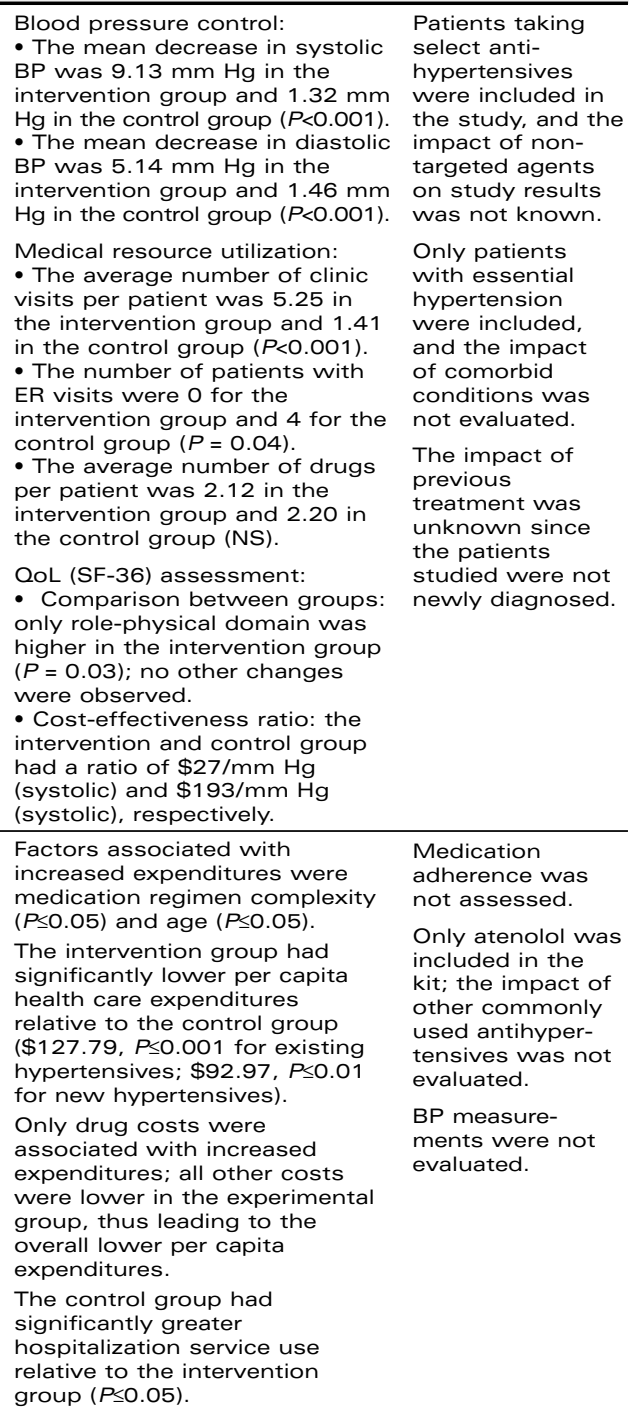

QoL (SF-36) assessment: $\quad$ studied were not

the patients$$
\text { (1) }
$$ 


\begin{tabular}{|c|c|c|c|c|}
\hline Study & Design & $\begin{array}{c}\text { Population / } \\
\text { Setting }\end{array}$ & $\begin{array}{l}\text { Evaluation } \\
\text { Time Frame } \\
\text { and Study } \\
\text { Sample (N) }\end{array}$ & $\begin{array}{c}\text { Relevant } \\
\text { Patient- } \\
\text { Selection } \\
\text { Criteria }\end{array}$ \\
\hline Barnett $^{18}$ & $\begin{array}{l}\text { Randomized } \\
\text { controlled } \\
\text { study }\end{array}$ & $\begin{array}{l}\text { Prepaid } \\
\text { group } \\
\text { practice of } \\
\text { a health plan }\end{array}$ & $\begin{array}{l}1 \text { and } 2 \\
\text { years } \\
N=52 \text { (C), } \\
63(\mathrm{I})\end{array}$ & $\begin{array}{l}\text { Patients with } \\
\text { elevated BP and } \\
\text { poor follow-up } \\
\text { care were } \\
\text { eligible. }\end{array}$ \\
\hline
\end{tabular}

Intervention Description A computer-based automated surveillance and reminder system was implemented to improve follow-up in patients with elevated diastolic BP $(>100 \mathrm{~mm} \mathrm{Hg}$ ). The intervention group received the computergenerated reminders, which included the need for follow-up care in addition to an encounter form (for recording when the next follow-up should occur and used for continuous monitoring). If timely follow-up did not occur, reminders would continue to be generated. Reminders were terminated once the follow-up occurred.

The control group did not receive reminders.

\begin{tabular}{llll}
\hline Skaer $^{19}$ & $\begin{array}{l}\text { Randomized, Medicaid } \\
\text { controlled } \\
\text { study }\end{array}$ & 1 year & Selected patients \\
& $\mathrm{N}=78(\mathrm{C})$, & included those \\
& $73(1,1) ; 85$ & with previously \\
& $(1,2) ; 68(1,3)$ & untreated \\
& hypertension \\
& who were aged \\
& $<65$ years and \\
& had a prescrip- \\
& tion for \\
& verapamil.
\end{tabular}

Implemented at 7 ambulatory care pharmacies, this intervention was composed of pharmacists providing refill reminders.

Control cohort received standard pharmaceutical care (medication counseling) each time antihypertensives were dispensed.

Intervention 1 was standard care at time of dispensing and a refill reminder 10 days prior to refill date via mail.

Intervention 2 was standard care at time of dispensing and provision of a unit-of-use packaging with each refill.

Intervention 3 was standard care, mailed reminders, and the unit-of-use package.

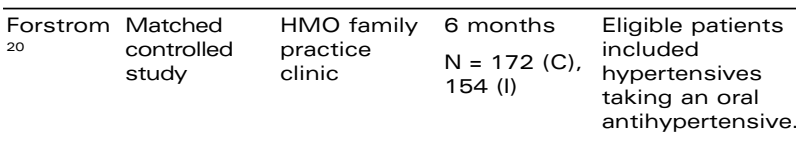

The intervention entailed pharmacists' monitoring of hypertensive patients. A formal, written consultation by pharmacists was placed in patient charts and flagged for physician review prior to the medical visit. The consult included suggestions for drug therapy alteration and a summary of the diagnosis, medication profile, pharmacist's recommendations and assessment of patient compliance, and the estimated cost impact of making the change. Physicians were notified if BP was not controlled, the patient was noncompliant, ADR was suspected, and a drug interaction was identified. The control group received no such monitoring.

The following therapeutic issues were targeted for monitoring: - HCTZ doses greater than 50 $\mathrm{mg}$ (no additional benefit), - patients on prazosin (expensive and effect wear-off over time) were recommended to switch therapies,

- step-down therapy was recommended with 6 months of maintained BP control
Outcomes Measured*

\section{2-month analysis:}

- Follow-up was attempted or achieved in $84 \%$ of patients in the intervention group and $25 \%$ in the control group

$$
(P<0.01)
$$

- Follow-up was accomplished (measured by recording of a repeat BP) in $49 \%$ of patients in the intervention group and $31 \%$ in the control group $(P<0.05)$.

24 month analysis:

- Follow-up was attempted or achieved in $98 \%$ of patients in the intervention group and $46 \%$ in the control group

(P<0.01)

- Follow-up was accomplished in $70 \%$ of patients in the intervention group and $52 \%$ in the control group $(P<0.05)$.

\section{Compliance was measured} using MPR:

- Intervention 3 demonstrated significantly higher MPR relative to the control, Intervention 1, and 2 groups ( $P \leq 0.05$ for all 3 comparisons). - The difference in MPR between Intervention 1 and 2 did not exist.

2. All interventions significantly increased drug costs $(P \leq 0.05)$.

Total health care costs were significantly less in Intervention $3(P \leq 0.05)$ compared with the control group, primarily due to significant reductions in hospitalization costs.

Total health care cost for Intervention 1 and 2 compared with the control group showed a decreasing trend; however, this was NS.

- The difference in average daily drug costs in the intervention and control groups was not statistically significant; however, there was a cant; however, there
slight trend toward a slight trend toward a
decreased cost in the interven tion group ( 5.6 cents per patient per day).

- The percentage of patients on HCTZ $>50 \mathrm{mg}$ was $26 \%$ in the intervention group and $72 \%$ in the control group $(P<0.01)$ - The percentage of patients on prazosin was $30 \%$ in the intervention group and $80 \%$ in the control group $(P<0.01)$
Major

Limitationst Effect on both systolic and not reported.

Antihypertensives used for the treatment of elevated BP was not assessed.

Very small number of patients were evaluated. prescribed verapamil

BP measurements were not evaluated. diastolic BP was

Only patients were evaluated.
Impact on the cost of other health care resource (aside from medications) utilization was Study patients included only those on ora antihypertensives. The intervention did not assess individuals with individuals with elevated BP not not assessed. 


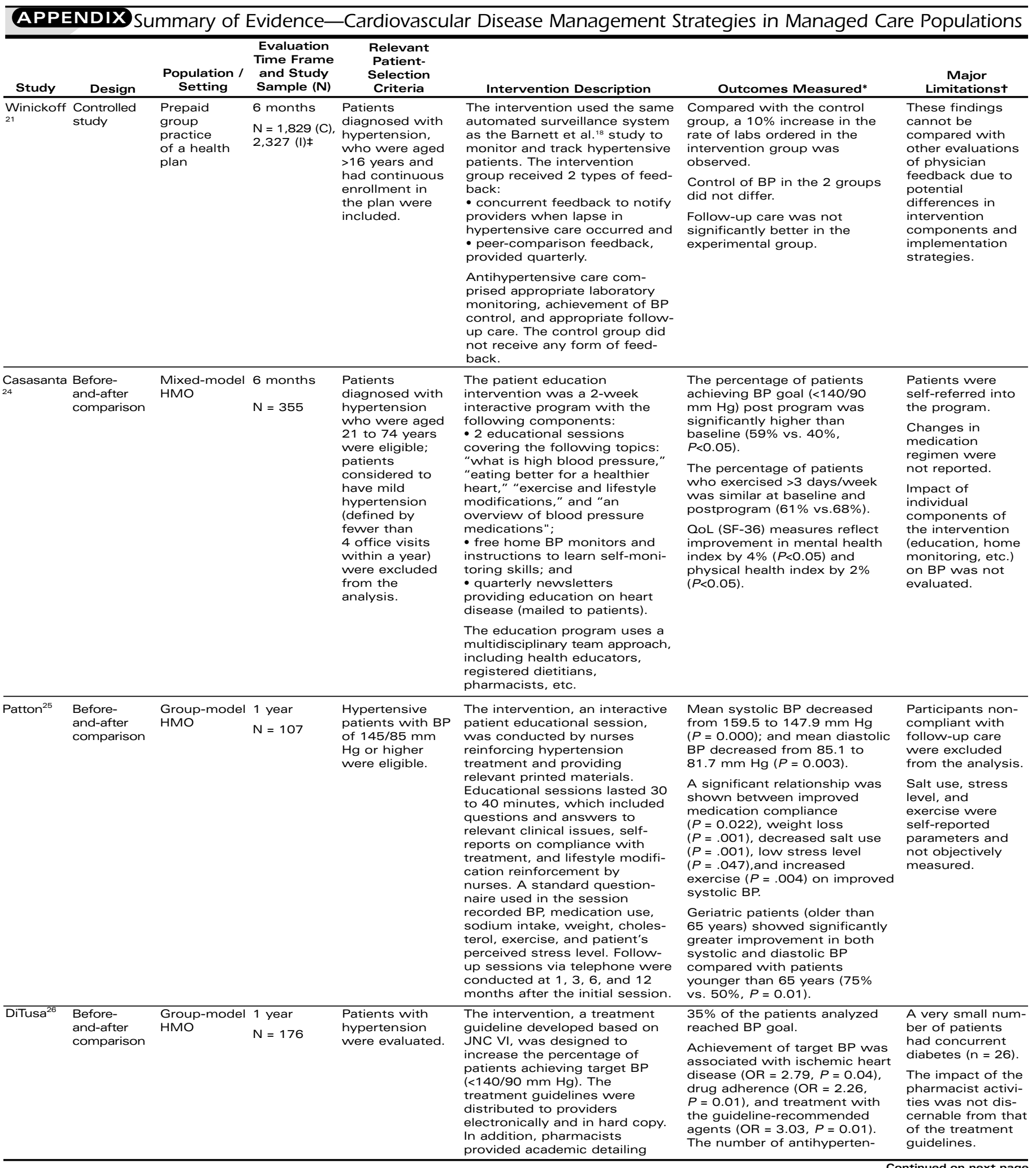




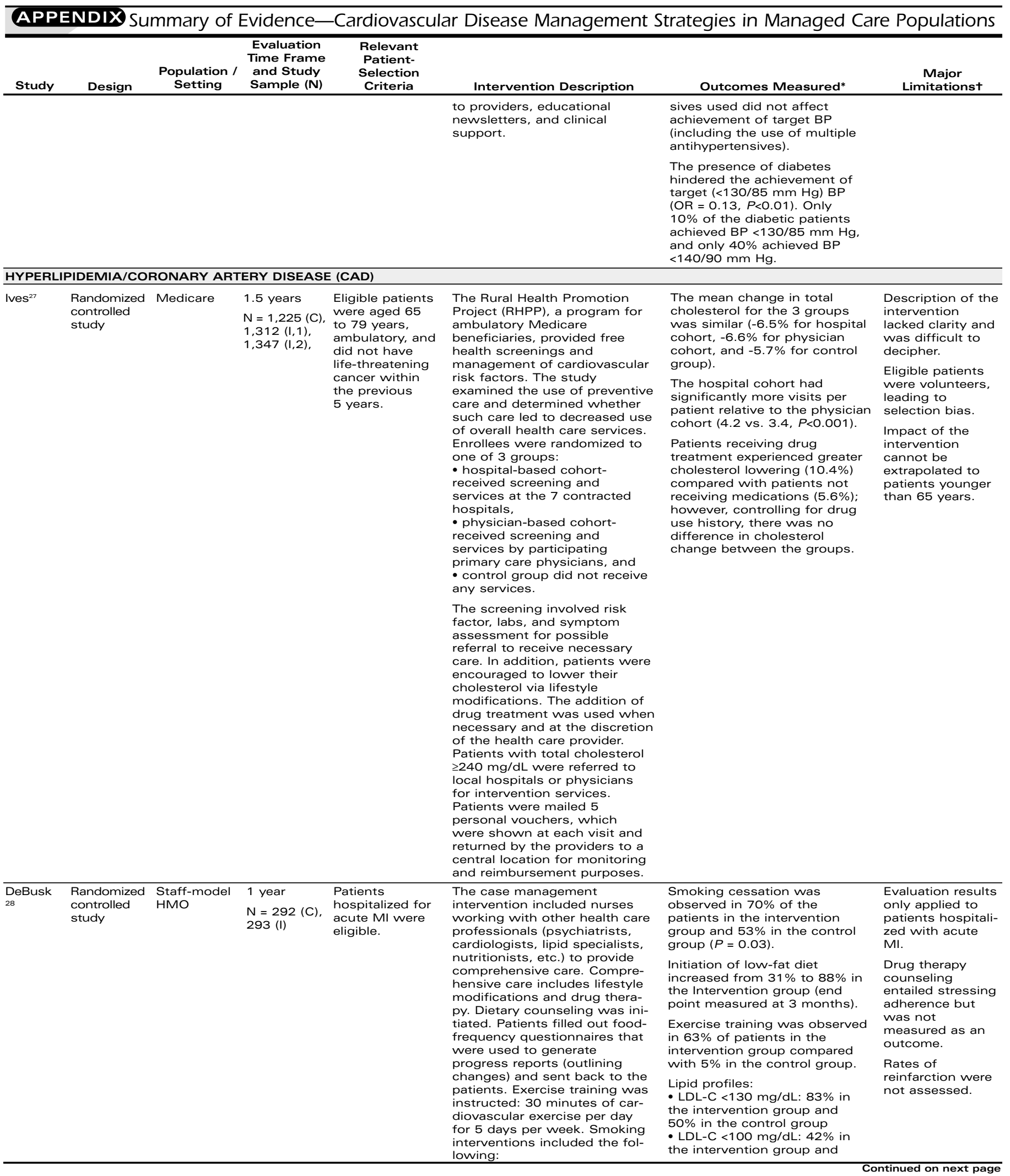




\begin{tabular}{|c|c|c|c|c|c|c|c|}
\hline \multirow[t]{5}{*}{ Study } & \multirow[t]{5}{*}{ Design } & \multirow[t]{5}{*}{$\begin{array}{c}\text { Population / } \\
\text { Setting }\end{array}$} & \multirow[t]{5}{*}{$\begin{array}{l}\text { Evaluation } \\
\text { Time Frame } \\
\text { and Study } \\
\text { Sample (N) } \\
\end{array}$} & \multirow[t]{5}{*}{$\begin{array}{l}\text { Relevant } \\
\text { Patient- } \\
\text { Selection } \\
\text { Criteria } \\
\end{array}$} & Intervention Description & Outcomes Measured* & $\begin{array}{c}\text { Major } \\
\text { Limitationst }\end{array}$ \\
\hline & & & & & \multirow{2}{*}{$\begin{array}{l}\text { - standardized physician } \\
\text { counseling, } \\
\text { - a relapse prevention manual } \\
\text { and a relaxation audiotape, } \\
\text { - an additional nurse visit (for } \\
\text { a relapse), and } \\
\text { - nicotine supplements, if } \\
\text { necessary. }\end{array}$} & $\begin{array}{l}15 \% \text { in the control group } \\
\text { - Significant changes in HDL-C } \\
\text { or triglycerides were not } \\
\text { observed }\end{array}$ & \\
\hline & & & & & & \multirow[t]{3}{*}{$\begin{array}{l}\text { Lipid-lowering drug use was } \\
\text { observed in } 90 \% \text { of the } \\
\text { intervention group compared } \\
\text { with } 21 \% \text { in the control group. }\end{array}$} & \\
\hline & & & & & $\begin{array}{l}\text { Drug therapy counseling } \\
\text { (stressing the importance of } \\
\text { compliance, management of } \\
\text { side effects, and proper lab } \\
\text { follow-up) was conducted if } \\
\text { drug therapy was required. } \\
\text { Maximum contact with case } \\
\text { managers was } 14 \text { calls, } 8 \text { lab } \\
\text { visits, and } 4 \text { office visits. }\end{array}$ & & \\
\hline & & & & & $\begin{array}{l}\text { The comprehensive care } \\
\text { compared with usual care. }\end{array}$ & & \\
\hline \multirow[t]{6}{*}{$\begin{array}{l}\text { Schectman } \\
29\end{array}$} & \multirow[t]{6}{*}{$\begin{array}{l}\text { Controlled } \\
\text { study }\end{array}$} & \multirow[t]{6}{*}{$\begin{array}{l}\text { Group-model } \\
\text { HMO }\end{array}$} & \multirow{6}{*}{$\begin{array}{l}18 \text { months } \\
\mathrm{N}=325\end{array}$} & \multirow{6}{*}{$\begin{array}{l}\text { Patients with } \\
\text { cholesterol } \geq 200 \\
\mathrm{mg} / \mathrm{dL} \text { at initial } \\
\text { assessment } \\
\text { were evaluated. }\end{array}$} & \multirow{6}{*}{$\begin{array}{l}\text { The intervention consisted of } \\
\text { patient counseling provided } \\
\text { by health care professionals. } \\
\text { As a result of the intervention, } \\
\text { patient knowledge of dietary } \\
\text { changes in hypercholes- } \\
\text { terolemia was assessed. } \\
\text { The intervention clinic had } \\
\text { American Heart Association } \\
\text { dietary educational materials } \\
\text { where the health care pro- } \\
\text { fessionals were encouraged } \\
\text { to use them for counseling } \\
\text { patients. The control site had } \\
\text { no such materials. Follow-up } \\
\text { was done by chart audit and } \\
\text { telephone interviews. }\end{array}$} & \multirow{2}{*}{$\begin{array}{l}\text { The association between the } \\
\text { amount of counseling recalled } \\
\text { by the patient and the amount } \\
\text { documented in the chart was } \\
\text { strong }(P<0.0001) \text {. }\end{array}$} & \multirow{6}{*}{$\begin{array}{l}\text { Lipid levels were } \\
\text { not assessed. } \\
\text { The length and } \\
\text { extent of } \\
\text { counseling } \\
\text { sessions were } \\
\text { not reported. } \\
\text { Dietary results } \\
\text { were assessed } \\
\text { using patient- } \\
\text { reported out- } \\
\text { comes and were } \\
\text { not subjective. }\end{array}$} \\
\hline & & & & & & & \\
\hline & & & & & & \multirow{3}{*}{$\begin{array}{l}\text { There was no relationship } \\
\text { between patient knowledge } \\
\text { and previous physician } \\
\text { educational counseling } \\
\text { received. } \\
\text { The only predictors of } \\
\text { knowledge were educational } \\
\text { level and baseline knowledge } \\
(P=0.03 \text { and } P=0.005 \\
\text { respectively). }\end{array}$} & \\
\hline & & & & & & & \\
\hline & & & & & & & \\
\hline & & & & & & $\begin{array}{l}\text { Patient-reported dietary change } \\
\text { was significantly associated } \\
\text { with knowledge score } \\
(P=0.0003) \text {. }\end{array}$ & \\
\hline \multirow[t]{5}{*}{ Khoury $^{22}$} & \multirow{5}{*}{$\begin{array}{l}\text { Before- } \\
\text { and-after } \\
\text { comparison }\end{array}$} & \multirow{5}{*}{$\begin{array}{l}\text { Staff-model } \\
\text { HMO }\end{array}$} & \multirow{5}{*}{$\begin{array}{l}18 \text { months } \\
N=7,001\end{array}$} & \multirow{5}{*}{$\begin{array}{l}\text { All patients with } \\
\text { CHD were } \\
\text { eligible. }\end{array}$} & \multirow{4}{*}{$\begin{array}{l}\text { The intervention targeted } \\
\text { physicians by providing } \\
\text { automatic feedback reports to } \\
\text { improve cholesterol manage- } \\
\text { ment. Reminder notices were } \\
\text { sent to } \\
\text { - providers with patients not } \\
\text { having LDL-C measured within } \\
\text { past } 2 \text { years } \\
\text { providers with patients } \\
\text { having LDL-C }>100 \text { mg/dL, or } \\
\text { - physicians who were non-- } \\
\text { compliant with NCEP ATP II } \\
\text { treatment guidelines. }\end{array}$} & \multirow{5}{*}{$\begin{array}{l}\text { The percentage of patients } \\
\text { without documented LDL-C } \\
\text { measurement decreased from } \\
30 \% \text { to } 18 \%(P<0.001) \text {. } \\
\text { The percentage of patients } \\
\text { attaining LDL-C goal }(\leq 100 \\
\mathrm{mg} / \mathrm{dL}) \text { increased from } 10 \% \text { to } \\
27 \%(P<0.001) \text {. }\end{array}$} & \multirow{5}{*}{$\begin{array}{l}\text { Factors such as } \\
\text { medication } \\
\text { regimen, diet, or } \\
\text { exercise were not } \\
\text { evaluated during } \\
\text { LDL-C assess- } \\
\text { ment. } \\
\text { Quarterly reports } \\
\text { were sent only to } \\
\text { primary care } \\
\text { physicians. }\end{array}$} \\
\hline & & & & & & & \\
\hline & & & & & & & \\
\hline & & & & & & & \\
\hline & & & & & $\begin{array}{l}\text { Primary care physicians also } \\
\text { received quarterly reports of } \\
\text { their performance and a list of } \\
\text { their CHD patients with } \\
\text { corresponding LDL-C levels. }\end{array}$ & & \\
\hline \multirow[t]{5}{*}{ Khoury $^{23}$} & \multirow[t]{5}{*}{$\begin{array}{l}\text { Before- } \\
\text { and-after } \\
\text { comparison }\end{array}$} & \multirow[t]{5}{*}{$\begin{array}{l}\text { Staff-model } \\
\text { HMO }\end{array}$} & \multirow[t]{5}{*}{$\begin{array}{l}2 \text { years } \\
N=7,066\end{array}$} & \multirow[t]{5}{*}{$\begin{array}{l}\text { Patients with } \\
\text { CHD and CHF } \\
\text { were eligible. }\end{array}$} & \multirow{3}{*}{$\begin{array}{l}\text { The intervention contained } \\
\text { computer-generated reminders } \\
\text { to improve physician com- } \\
\text { pliance with clinical guidelines. } \\
\text { The following issues generated } \\
\text { reminders: } \\
\text { - patients with CHD who were } \\
\text { not on aspirin, } \\
\text { - patients with CHF who were } \\
\text { not on an ACEl, and } \\
\text { - patients with a history of MI } \\
\text { in the past } 2 \text { years who were } \\
\text { not on a beta-blocker. }\end{array}$} & $\begin{array}{l}\text { The percentage of patients } \\
\text { using aspirin increased from } \\
56 \% \text { to } 81 \%(P<0.001) \text {. }\end{array}$ & $\begin{array}{l}\text { Impact of individ- } \\
\text { ual intervention } \\
\text { components was } \\
\text { not assessed. }\end{array}$ \\
\hline & & & & & & $\begin{array}{l}\text { achieving LDL-C }<100 \mathrm{mg} / \mathrm{dL} \\
\text { (evaluation period of } 7 \text { months) } \\
\text { increased from } 10.3 \% \text { to } \\
18.9 \%(P<0.001) \text {. }\end{array}$ & $\begin{array}{l}\text { Impact of ACEI } \\
\text { use on NYHA } \\
\text { functional class } \\
\text { was not evaluated. }\end{array}$ \\
\hline & & & & & & $\begin{array}{l}\text { The percentage of patients not } \\
\text { having an LDL-C screening in } \\
\text { the past } 2 \text { years decreased } \\
\text { from } 30.3 \% \text { to } 24.2 \%\end{array}$ & $\begin{array}{l}\text { Percentage of } \\
\text { patients on cho- } \\
\text { lesterol-lowering } \\
\text { diet or lipid-lower- }\end{array}$ \\
\hline & & & & & Patients with CAD and LDL-C & & ing medication \\
\hline & & & & & $\begin{array}{l}>100 \mathrm{mg} / \mathrm{dL} \text { received a } \\
\text { reminder to initiate a choles- }\end{array}$ & $\begin{array}{l}\text { The percentage of patients } \\
\text { using ACEI increased from }\end{array}$ & \\
\hline
\end{tabular}




\begin{tabular}{|c|c|c|c|c|c|c|c|}
\hline Study & Design & $\begin{array}{l}\text { Population / } \\
\text { Setting }\end{array}$ & $\begin{array}{c}\text { Evaluation } \\
\text { Time Frame } \\
\text { and Study } \\
\text { Sample (N) }\end{array}$ & $\begin{array}{l}\text { Relevant } \\
\text { Patient- } \\
\text { Selection } \\
\text { Criteria } \\
\end{array}$ & Intervention Description & Outcomes Measured* & $\begin{array}{c}\text { Major } \\
\text { Limitationst }\end{array}$ \\
\hline & & & & & $\begin{array}{l}\text { terol-lowering diet or a lipid- } \\
\text { lowering agent. The reminders } \\
\text { were linked to the automated } \\
\text { medical record system and } \\
\text { released immediately prior to } \\
\text { the patient visit. The second } \\
\text { phase of the intervention was } \\
\text { implemented } 6 \text { months after } \\
\text { the initial reminders, where } \\
\text { physicians received individual } \\
\text { performance reports compared } \\
\text { with peer performance. The } \\
\text { aspirin reminder was linked to } \\
\text { financial incentives; compliance } \\
\text { with aspirin-use guidelines } \\
\text { could increase provider compen- } \\
\text { sation by as much as } 7 \% \text {. }\end{array}$ & $\begin{array}{l}54 \% \text { to } 67 \% \text { ( } P<0.001 \text {. } \\
\text { Beta blocker use was a HEDIS } \\
\text { measurement and was } \\
\text { therefore compared with } \\
\text { NCQA benchmarks. } \\
\text { Compliance with beta-blocker } \\
\text { use } 2 \text { weeks after MI was } \\
90.2 \% \text { postintervention; } \\
\text { however, NCQA } 1996 \\
\text { benchmarks reported a range } \\
\text { of } 30 \% \text { to } 100 \% \text { compliance in } \\
\text { other plans. }\end{array}$ & \\
\hline \multirow[t]{6}{*}{$\begin{array}{l}\text { Merenich } \\
\text { 30 }\end{array}$} & \multirow[t]{6}{*}{$\begin{array}{l}\text { Before- } \\
\text { and-after } \\
\text { comparison }\end{array}$} & \multirow[t]{6}{*}{$\begin{array}{l}\text { Staff-model } \\
\text { HMO }\end{array}$} & \multirow[t]{6}{*}{$\begin{array}{l}10 \text { months } \\
\mathrm{N}=1,716\end{array}$} & \multirow{6}{*}{$\begin{array}{l}\text { Patients with } \\
\text { hyperlipidemia } \\
\text { and CAD were } \\
\text { eligible. }\end{array}$} & \multirow{6}{*}{$\begin{array}{l}\text { The Clinical Pharmacy Cardiac } \\
\text { Risk Service (CPCRS) was cre- } \\
\text { ated to provide outpatient man- } \\
\text { agement of patients with heart } \\
\text { disease. This was a pharmacist } \\
\text { managed, physician-monitored } \\
\text { service for lipid management. } \\
\text { Pharmacists ordered labs, } \\
\text { adjusted lipid medications, and } \\
\text { scheduled follow-up appoint- } \\
\text { ments. Patients could be con- } \\
\text { tacted by phone, sent lab data } \\
\text { via mail, or receive one-on-one } \\
\text { visits when necessary. Coun- } \\
\text { seling by pharmacists included } \\
\text { extensive topics (combination } \\
\text { drug regimens, use of beta- } \\
\text { blockers and ACEl post- MI, } \\
\text { issues of estrogen treatment, } \\
\text { and drug interactions). CPCRS } \\
\text { participants were encouraged } \\
\text { to attend educational seminars } \\
\text { related to heart disease. }\end{array}$} & $\begin{array}{l}\text { The percentage of patients on } \\
\text { aspirin or antiplatelet therapy } \\
\text { increased by } 7 \% \text { from baseline }\end{array}$ & \multirow{6}{*}{$\begin{array}{l}\text { Statistical } \\
\text { analyses was } \\
\text { not reported. } \\
\text { Impact of LDL-C } \\
\text { improvement on } \\
\text { morbidity and } \\
\text { total health care } \\
\text { utilization was } \\
\text { not assessed. }\end{array}$} \\
\hline & & & & & & $\begin{array}{l}(90 \% \text { to } 97 \%) \text {; statistical tests } \\
\text { for all end points were not } \\
\text { reported. }\end{array}$ & \\
\hline & & & & & & $\begin{array}{l}\text { The percentage of beta-blocker } \\
\text { use in patients post Ml } \\
\text { increased from } 85 \% \text { to } 92 \% \text {. }\end{array}$ & \\
\hline & & & & & & $\begin{array}{l}\text { LDL-C screening rate increased } \\
\text { from } 55 \% \text { to } 97 \% \text {. }\end{array}$ & \\
\hline & & & & & & $\begin{array}{l}\text { The percentage of patients } \\
\text { achieving LDL-C }<130 \mathrm{mg} / \mathrm{dL} \\
\text { increased from } 58 \% \text { to } 84 \% \text {; } \\
\text { and LDL-C }<100 \mathrm{mg} / \mathrm{dL} \\
\text { increased from } 22 \% \text { to } 48 \% \text {. }\end{array}$ & \\
\hline & & & & & & $\begin{array}{l}\text { The percentage of patients } \\
\text { with LDL-C }>130 \mathrm{mg} / \mathrm{dL} \text { and } \\
\text { not on cholesterol-lowering } \\
\text { medications dropped from } 12 \% \\
\text { to } 3 \% \text {. }\end{array}$ & \\
\hline
\end{tabular}

* $P$ values reported where available.

+ Major limitations other than those inherent to the study design.

$\neq$ Reflects number of patients with follow-up data.

$A C E I$ = angiotensin-converting enzyme inhibitor; $A D R=$ adverse drug reaction; $A R B=$ angiotensin receptor blocker; $B P=$ blood pressure; $C=$ control group; $C A D=$ coronary artery disease; $C H F=$ congestive heart failure; $D M=$ disease management; $E R=$ emergency room visit; HCTZ = hydrochlorothiazide; HDL-C = high-density lipoprotein cholesterol; HEDIS = Health Plan Employer Data and Information Set; $H M O=$ health maintenance organization; HTN = hypertension; I = intervention group; JNC VI = Joint National Committee on Prevention, Detection,

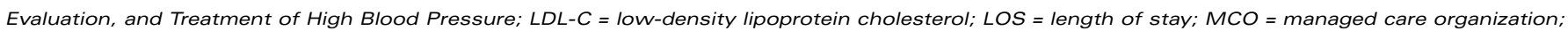
$M I=$ myocardial infarction; MPR = medication possession ratio; NCEP ATP = National Cholesterol Education Program Adult Treatment Panel; NCQA = National Committee for Quality Assurance; NS = not significant; NYHA = New York Heart Association; OR = odds ratio; QI= quality improvement; $\mathrm{QOL}=$ quality of life; SF-36 = medical outcomes study, short form-36. 